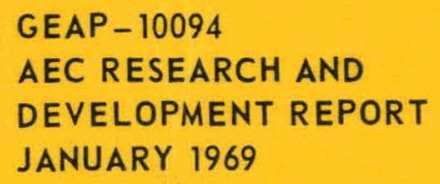

\title{
A STUDY OF ADIABATIC, FULLY-DEVELOPED, ANNULAR-DISPERSED TWO-PHASE FLOW IN A VERTICAL ROUND TUBE
}

R.L. SIMPSON

U.S. ATOMIC ENERGY COMMISSION CONTRACT AT(04-3)-189 PROJECT AGREEMENT 44 


\section{DISCLAIMER}

This report was prepared as an account of work sponsored by an agency of the United States Government. Neither the United States Government nor any agency Thereof, nor any of their employees, makes any warranty, express or implied, or assumes any legal liability or responsibility for the accuracy, completeness, or usefulness of any information, apparatus, product, or process disclosed, or represents that its use would not infringe privately owned rights. Reference herein to any specific commercial product, process, or service by trade name, trademark, manufacturer, or otherwise does not necessarily constitute or imply its endorsement, recommendation, or favoring by the United States Government or any agency thereof. The views and opinions of authors expressed herein do not necessarily state or reflect those of the United States Government or any agency thereof. 


\section{DISCLAIMER}

Portions of this document may be illegible in electronic image products. Images are produced from the best available original document. 


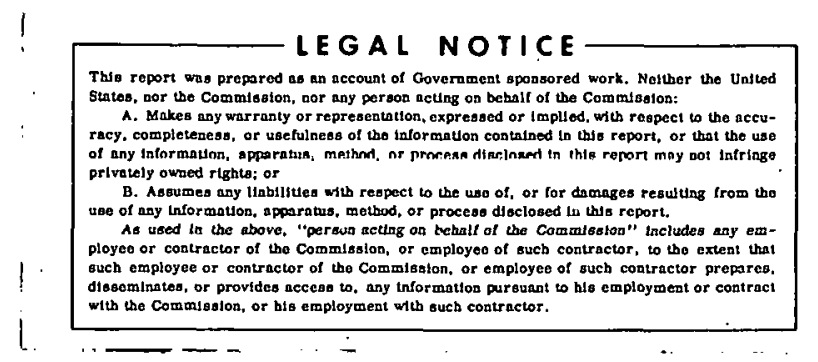

GEAP-10094

AEC Resitarch and Development Report

January 1969

A STUDY OF ADIABATIC,

FULLY-DEVELOPED, ANNULAR-DISPERSED

TWO-PHASE FLOW IN A VERTICAL ROUND TUBE

R. L. Simpson

Approved:

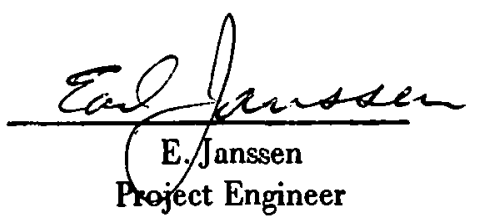

Approved:

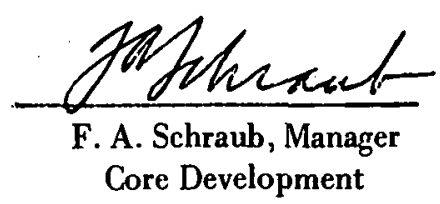

U.S. Atomic Energy Commission

Contract AT(04-3)-189

Project Agreement 44

Printed in U.S.A. Available from the

Clearing House for Federal Scientific and Technical Information

National Bureau of Standards, U.S. Department of Commerce

Springfield, Virginia

Price: $\$ 3.00$ per copy 


\section{LEGAL NO'TICE}

This report was prepared as an account of Government sponsored work. Neither the United States, nor the Commission, nor any person acting on bebalf of the Commissior:

A. Makes any warranty or representation, expressed or implied, with respect to the accuracy, completeness, or usefulness of the information contained in this report, or that the use of any information, apparatus, method, or process disclosed in this report may not infringe privately owned rights; or

B. Assumes any liabilities with respect to the use of, or for damages resulting from the use of any information, apparatus, method, or process disclosed in this report.

As used in the above, "person acting on bebalf of the Commission" includes any employee or contractor of the Commission, or employee of sucb contractor, to the extent that sucb employee or contractor of the Commission, or employee of such contractor prepares, disseminates, or provides access to, any information pursuant to bis employment or contract with the Commission, or his employment with such contractor. 


\section{TABLE OF CONTENTS}

Summary ...................... vii

1. Introduction ....................... 1

2. The Film Liquid Flow Rate-

Liquid Film Thickness Relationship

in Adiabatic Two-Phase Flow . . . . . . . . . . . . . 1

3. Entrainment Fraction in Adiabatic

Annular-Dispersed Two-Phase Flow . . . . . . . . . . . . . 3

4. Core Gas Linear Velocity Profiles . . . . . . . . . . . . . . . 12

5. Liquid Volumetric Distribution in the Gas Core . . . . . . . . . . . . . . . . . . .

6. The Prediction of Pressure Drop, Mean Void Fraction and Film Thickness . . . . . . . . . . . . 19

7. Concluding Comments .................. . 27

Nomenclature . . . . . . . . . . . . . . . . 28

Acknowledgments . . . . . . . . . . . . . . . 29

References ..................... . 29

External Distribution . . . . . . . . . . . . . . 31 


\section{LIST OF ILLUSTRATIONS}

Figure

Title

1 Dimensionless Film Liquid Flow Rate

Vcrsus Film Thickness . . . . . . . . . . . . . . . . . . . 4

2 Data Presented by Paleev and Fillipovich .................. 6

3 Further Entrainment Data .................. 7

$4 \quad$ Data of Steen $($ See Ref. 32) . . . . . . . . . . . . . . . 9

5 Steen's Entrainment Data in Terms of $\Pi_{3} \ldots \ldots \ldots$

6 Entrainment in 'Terms of $\Pi_{3} \ldots \ldots \ldots \ldots \ldots$

7 Corc Cas Lincar Velocity Data of Schraub,

Simpson, and Janssen (See Ref. 31) . . . . . . . . . . . . 13

8 Data of Alia, et al. (See Ref. 10) . . . . . . . . . . . . . 14

9 Radial Distribution of Liquid, Data of

Schraub, Simpson, and Janssen (Scc Rcf. 31) . . . . . . . . . . . 16

10 Radial Distribution of Liquid, Data of

Cousins and Hewitt (See Ref. 38) . . . . . . . . . . . . . . 17

11 Comparison of Data Reduced by the

Isokinetic and British Homogeneous Mlethods . . . . . . . . . . . . 18

12 Schematic Diagram of Pressure Drop and Void

Fraction Computation Method

13 Comparison of Calculated and Experimental Pressure

Drop and Void Fraction for the Data of Schraub,

Simpson, and Janssen (Ref. 31)

14. Comparison of Calculated and Experimental

Liquid Film Thickness for the Data of

Schraub, Simpson, and Janssen (Ref. 31) 


\section{SUMMARY}

The detailed time-averaged flow structure of upward, annular-mist, two-phase flow is used to predict pressure drop, film liquid thickness, and average void fraction, which are compared with experimental results. The several flow phenomena incorporated in this computational scheme are expressed by four phenomenological models. Many sets of experimental data are rationalized to form a consensus upon which to test these models.

\section{- FILM LIQUID FLOW RATE - LIQUID FILM THICKNESS RELATIONSHIP.IN ADIABATIC TWO.PHASE. FLOW}

The film liquid flow rate-liquid film thickness data of Alia, et al., and Quandt are presented along with the data of Schraub, Simpson, and Janssen. These data, taken with different fluids and different geometries, are in good agreement and indicate a universal $\mathrm{G}_{\mathrm{f}}^{+}$versus $\delta^{+}$ relationship for pressures in the range $1 \mathrm{~atm}<\mathrm{P}<22$ atm, $0.05<X<0.74$, and mass flow rates between 0.1 $\times 10^{6}$ and $2 \times 10^{6} \mathrm{lb} / \mathrm{h}-\mathrm{ft}^{2}$. An analysis, using mixing length theory with allowance for voids in the liquid film by $a=\mathrm{CU}^{+}$, is in good agreement with these experimental data.

\section{- ENTRAINMENT FRACTION IN FULLY-DEVELOPED, ANNULAR-DISPERSED TWO-PHASE FLOW}

Much entrainment fraction data from adiabatic annular dispersed two-phase flows have been examined. Using the entrainment fraction independent variable of Paleev and Fillipovich, one is able to account for area, density, surface tension, and flow rate effects for fully developed flows. The data of Steen, taken with several fluids covering an extensive range of liquid viscosities, indicate that the Paleev and Fillipovich variable does not account correctly for the liquid viscosity. Based on Steen's silicone data, a modified Paleev and Fillipovich variable that correctly accounts for the liquid viscosity is presented. Also presented is the resulting correlation of the data of Steen, Minh and Huyghe, and Alia, et al., with this variable.

\section{- CORE LINEAR GAS VELOCITY PROFILES}

The core gas linear velocity profiles from the Schraub, Simpson, and Janssen annular-dispersed round-tube data are found to agree with the results of Alia, et al., in terms of $\left(\mathrm{U}_{\mathrm{Gg}}-\mathrm{U}_{\mathrm{g}}\right) / \mathrm{U}_{\tau \mathrm{g}}$ versus $\mathrm{y} / \mathrm{R}$. These profiles, for flow qualities greater than $11 \%$, lie between single-phase pipe and flat-plate correlations.

\section{- LIQUID VOLUMETRIC DISTRIBUTION MODEL FOR THE GAS CORE}

The liquid volumetric concentration in the gas core is not uniform at the asymptotic condition. Since droplet concentration gradient diffusion must not be the only transport mechanism, the idea of preferential turbulent drift of droplets toward the wall is briefly investigated. However, it is concluded that the unity core local slip ratio assumption is a simple and reasonable assumption since it produces a rather flat liquid volumetric distribution and eliminates the need for the local slip ratio to vary over the core.

The results from the computational scheme indicate that the entrainment fraction and pressure drop are intimately related. When a known entrainment is input, the pressure drop is predicted within $25 \%$ of the experimental value for $X>25 \%$. In many cases, the agreement was better than $25 \%$, and improves as the mean quality is increased. Since it is apparent that the entrainment fraction is rig dependent to some degree, the pressure drop will be affected accordingly; i.e., an increase in entrainment fraction will produce a decrease in pressure drop. It was also found that when the pressure drop was closely predicted, the film thickness and average void fraction were also closely predicted. 


\section{INTRODUCTION}

This study concerns the upward flow of an adiabatic two-phase mixture in a round tube for the annular-mist flow regime. The flow is not simple. Liquid flows in a thin film along the tube wall. Large waves exist on the liquid film surface. Other liquid is entrained in the gaseous core. Eventually, an equilibrium between core droplet deposition and liquid film entrainment rates is attained, and the entrainment fraction becomes essentially constant. The flow is fully developed at this asymptotic condition.

This study has a two-fold objective:

- To rationalize existing experimental results to form a consensus upon which to test semi-empirical modeling, and

- To model the several flow phenomena and demonstrate the inter-model consistency of the results.

To meet the first objective, four phenomenological models, or correlations, are developed and compared with experimental data:

a. The film liquid flow rate-liquid film thickness relationship.

b. The fraction of liquid entrained in the gas core model,

c. The core gas linear velocity profile relationship, and

d. A liquid volumetric distribution model for the gas core. These four models are considered together to produce average void fraction, liquid film thickness, and pressure drop predictions that are compared with experimental results. The effect of perturbations of the individual models on the final results are also considered.

\section{THE FILM LIQUID FLOW RATE-LIQUID FILM THICKNESS RELATIONSHIP IN ADIABATIC TWO-PHASE FLOW}

\subsection{EXPERIMENTAL RESULTS}

In an annular two-phase flow there is apparently a distinct liquid film covering the conduit walls, and a gas flow with entrained liquid droplets in the core. Several

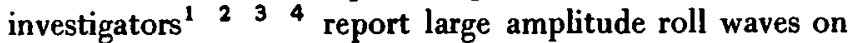
the surface of the liquid film so that, in general, the interface is not smooth. To describe this type of flow, it is useful to describe the relationship between the mean liquid film flow rate and the mean liquid film thickness even though these waves are not explicitly considered. Only upward co-current flow is considered here.

Several investigators have measured either the mean liquid film flow rate ${ }^{s}$ or the mean liquid film thickness 1.67 .8 . The investigations of Quandt ${ }^{9}$ and Alia, et al., ${ }^{10}$ and the present program are known to report direct measurements of both quantities for adiabatic flow. Quandt used a $1 / 4 \times 3$ inch rectangular plexiglass channel for visual observations in a vertical upward co-current airwater flow at near-atmospheric conditions. He used a dye concentration technique (which he described in detail) to determine the liquid film flow rate and liquid film thickness.

Alia, et al., studied argon-water and argon-ethyl alcohol flows in a l-inch round tube at pressures between 11 and 22 atmospheres, flow rates between $0.2 \times 10^{6}$ and $2 \times 10^{6}$ $\mathrm{lb} / \mathrm{h}-\mathrm{ft}^{2}$, and qualities between 5 and $79 \%$. An isokinetic sampling scoop, forming a segment of an annulue, was traversed through the liquid film to obtain the total liquid flowing between the wall and some position $y$ in the film. The thickness of the liquid film was determined by the film conductance method, described in the Tenth Quarterly Progress Report ${ }^{11}$.

In the P.A. 44 program, air-water flows in a 1 -inch round tube at about 85 psia were run with an approximately constant air flow rate of $0.11 \mathrm{lb} / \mathrm{sec}$ for qualities between 11 and $62 \%$. The liquid film was sucked off through a porous sinter, as described in Quarterly Progress Reports 4 and $5^{12}$, while the liquid film thickness was determined by the needle contact method described in Quarterly Report Numbers 7 and $10^{13} 11$.

All results reported from these investigations are shown in Figure 1 as $\mathrm{G}_{\mathrm{f}}^{+}$versus $\delta^{+}$, where

$$
\mathrm{G}_{\mathrm{f}}^{+} \equiv \frac{\delta \mathrm{G}_{\mathrm{f}}}{\mu_{\ell}}, \delta^{+} \equiv \frac{\delta}{\nu_{\ell}} \cdot \sqrt{\frac{\tau_{\mathrm{Wg}}}{\rho_{\ell}}},
$$

and $\delta=$ film thickness.

Quandt and the P.A. 44 investigators determined $\tau_{\mathbb{W}}$ from pressure drop and "quick closing valve" void fraction data, while Alia, et al., measured $\tau_{\mathbb{W}}$ directly with a floating sleeve hydraulic method described in Reference 14. Note that there is substantial agreement among these data, with the best agreement being between the data of Quandt and of Alia, et al.

The uncertainties associated with these data should be borne in mind. The liquid film flow rate obtained by the porous sinter method cannot be distinctly determined as 
shown in Figure A-16 of Reference 12. This problem is more acute at low quality flows (large $\delta^{+}$). In the needle contact method, the needle can disturb the liquid film by contact hysteresis ${ }^{15}$ and by deflecting gas into the liquid film. Alia, et al., point out that air in the liquid film, as indicated by the scoop data, causes some uncertainty in the relationship between the electrical conductance film thickness and the actual extension of the region where the liquid is the continuous phase. Quandt did not estimate the uncertainty of his method, except to state that there was less than $\pm 25 \%$ scatter in his data.

Alia, et al., presented the empirical equation, $G_{f}^{+}=5.3$ $\left(\delta^{+}\right)^{1 . I}$, fitted through their data which agrees well with the other data as a whole. It is interesting to note that Alia, et al., found that the $\mathrm{G}^{+}$between the wall and a given $\mathrm{y}^{+}$in the film also followed this relation until $\mathrm{y}^{+} \geqslant \delta^{+}$. For $\mathrm{y}^{+}>$ $\delta^{+}$, the data departed markedly from this relation.

The good agreement of these data taken with different fluids and different geometries indicates a universal $\mathrm{G}^{+}$ versus $\delta^{+}$relationship for pressures in the. range $1 \mathrm{~atm}<P$ $<22$ atm, $0.05<\mathrm{X}<0.74$, and mass flow rates between $0.1 \times 10^{6}$ and $2 \times 10^{6} \mathrm{lb} / \mathrm{h}-\mathrm{ft}^{2}$.

\subsection{ANALYSIS}

As a first approximation, several investigators $916 \quad 17$ have assumed that the single-phase "law of the wall" of the mean velocity profile applies to the film liquid and that

$$
\frac{G_{f} \delta}{\mu_{\ell}}=G_{f}^{+}=\int_{0}^{\delta^{+}} U_{l}^{+} d y_{\ell}^{+} \text {. }
$$

Levy ${ }^{16}$ used a three-layer Von Karman $\mathrm{U}_{\ell}^{+}$versus $\mathrm{y}_{\ell}^{+}$model, - while Ilewitt ${ }^{17}$. used a two-layer model. The results of these anulyses for the range of presented data are shown in Figure 1 to overestimate $\mathrm{G}_{\mathrm{f}}^{+}$about 30 to $60 \%$ at a given $\delta^{+}$. Note that the Ilewitt model does not predict $\mathrm{G}_{f}^{+}$as a unique function of $\mathbf{y}_{\ell}^{+}$.

This general approach seemis reasonable, except for the fact that the possibility of gas flow in the film has not been considered. Alia, et al., ${ }^{10}$ report void fractions of the order of 0.5 at the outer edge of the film from their film isokinetic sampling data. Hanratty and Hershman ${ }^{3}$ report large roll waves on the film surface that could conceivably entrain gas bubbles intu the film. Hence, allowance for gas will be made in the present analysis.

In the present analysis, a two-layer model will be used to derive the film velocity profile: (1) a viscous sublayer near the wall $\left(y^{+} \leqslant 11\right)$ and (2) a fully turbulent region described by the Prandtl mixing length theory. The void fraction is considered a function of $\mathrm{U}^{+}$(or $\mathrm{y}^{+}$), to be consistent with the idea that $\mathrm{G}^{+}$is a universal function of $y^{+}$. Two different liquid film void fraction distributions, each a unique function of $\mathrm{U}^{+}$, will be considered here. The first,

$$
a=\mathrm{CU}^{+},
$$

assumes that entrained air is distributed throughout the film. The motivation is that

$$
a \rightarrow 0 \text { as } \mathrm{U} \rightarrow 0 \text {, while } a \rightarrow 1 \text { as } \mathrm{U}_{\mathrm{g}} / \mathrm{U}_{\mathrm{g}}, \mathrm{E} \rightarrow 1 \text {. }
$$

If Equation (2-3a) is approximately

$$
a \sim \mathrm{U}_{\mathrm{g}} / \mathrm{U}_{\mathrm{g}}, \mathrm{G},
$$

then the constant

$$
\mathrm{C} \approx \mathrm{U}_{\tau} / \mathrm{U}_{\mathrm{g}}, \mathrm{E}
$$

can be evaluated by the isokinetic sampling data of Reference 19 , which produces $\mathrm{C} \approx 0\left(10^{-2}\right)$. Furthermore, with $\alpha$ of the order of 0.5 at the outer film edge, it is necessary that $\mathrm{C} \approx 0.03$ for $\mathrm{U}_{\ell}^{+}$of the order of 10 to 20 for $10<\mathrm{y}^{+}<200$.

The second distribution approximates the void fraction distribution obtained from the CISE film isokinetic sampling data ${ }^{10} 14$ using a local slip ratio of 1 and presented in Reference 10. For $\mathrm{y}^{+} \leqslant 11, a=0$, while $u \sim \ln \left|y^{+}\right|$out to the film edge, where $a \approx 0.5$. Since $\mathrm{U}^{+}-\ln \left|\mathrm{y}^{+}\right|$, then

$$
a=\mathrm{AU}^{+}+\mathrm{B}
$$

is an approximate relation filling the data with $A=0.082$ and $B=-0.9$.

A force balance on the film for a given yosition produces

$$
r-T_{W}+\rho_{\ell} \int_{0}^{y}(i-a) g d y+\frac{d P}{d z} y
$$

or

$$
\frac{\tau}{{ }^{T_{W}}}=1+\frac{\nu_{\ell} \mathrm{g}}{\mathrm{U}_{\tau \ell^{3}}}\left[\int_{0}^{\mathrm{y}^{+}}(1-a) \mathrm{dy}^{+}+\frac{\mathrm{y}_{\ell}^{+}}{p_{\ell} g} \frac{\mathrm{dP}}{i \mathrm{dz}}\right]
$$

for small $y / R$ values. The coefficient of the bracketed term on the right side of Equation (2-5) is of the order of $1 \sigma^{3}$ while the bracketed quantities tend to cancel. Hence, in the present analysis 


$$
\tau \approx T_{W^{*}}
$$

In the viscous sublayer;

$$
\tau_{W}=\mu \frac{\partial U}{\partial y},
$$

with

$\mu=\mu_{\ell}(1 \cdot a)+\mu_{\mathrm{g}} a$.

For the first void distribution,

$$
\mu \approx \mu_{\ell}\left(1-\mathrm{CU}^{+}\right) \text {since } \mu_{\mathrm{g}} / \mu_{\ell} \ll 1
$$

Thus,

$$
\mathrm{U}_{\ell}^{+} \cdot \frac{\mathrm{CU}_{\ell}^{+2}}{2}=\mathrm{y}_{\ell}^{+}
$$

for the sublayer. With $a=0$ in the sublayer, the second void distribution produces the classical single phase relation for $\mathrm{U}_{\ell}^{+} \leqslant 11$,

$$
\mathrm{U}_{\ell}^{+}=\mathrm{y}_{\ell}^{+} \cdot
$$

For the fully-turbulent region, the mixing length relation,

$$
\tau=\dot{\rho} \ell^{2}\left[\frac{\partial \mathrm{U}}{\partial \mathrm{y}}\right]^{2}
$$

will be used with

$$
\rho=\rho_{\ell}\left[1-\left(1-\rho_{\mathrm{g}} / \rho_{\ell}\right) a\right],
$$

and $\ell=0.4 \mathrm{y}$.

For $a=0.03 \mathrm{U}^{+}$and $\rho_{\mathrm{g}} / \rho_{\ell} \ll 1$, one obtains

$$
\frac{\mathrm{dy}_{\ell}^{+}}{0.4 \mathrm{y}_{\ell}^{+}}=\sqrt{1-0.03 \mathrm{U}_{\ell}^{+}} \cdot \mathrm{dU}_{\ell}^{+}
$$

from Equations (2-9) and (2-10). Integrating, using the single-phase constants, ${ }^{19} \mathrm{U}^{+}=11$ at $\mathrm{y}^{+}=11$, produces

$$
\frac{1}{0.4} \ln \left|\frac{\mathrm{y}_{\ell}^{+}}{11}\right|=\frac{-2 / 3}{0.03} \quad\left\{\left(1-0.03 \mathrm{U}_{\ell}^{+}\right)^{3 / 2}-(0.67)^{3 / 2}\right\}
$$

Equation (2-12) applies outside the point of intersection of Equations (2-7) and (2-12), while Equation (2-7) applies inside that point. The justification for using the single-phase constants is somewhat intuitive since these constants produce agreement of the mixing length theory with single-phase velocity profile data for mass transfer and moderate pressure gradient cases ${ }^{19} 20$.

Likewise, using Equations (2-9) and (2-10) and $\rho_{\mathrm{g}} / \rho_{\ell}$ $<1$ with the second void distribution, $a=0.082 \mathrm{U}^{+}-0.9$, produces

$$
\frac{\mathrm{dy}_{\ell}^{+}}{0.4_{y_{\ell}^{+}}^{+}}=\sqrt{1-\left(0.082 \mathrm{U}_{\ell}^{+}-0.9\right)} d \mathrm{U}_{\ell}^{+}
$$

Integrating and using the single-phase constants produces

$$
\frac{1}{0.4} \ln \left|\frac{y_{\ell}^{+}}{11}\right|=\frac{.2 / 3}{0.082} \quad\left\{\left(1.9-0.082 \mathrm{U}_{\ell}^{+}\right)^{3 / 2} \cdot 1\right\} \text {. }
$$

To obtain $\mathrm{G}_{f}^{+}$, one finds that

$$
\mathrm{G}_{\mathrm{f}}^{+}=\int_{0}^{\delta} \frac{\rho \mathrm{Udy}}{\mu_{\ell}}=\int_{0}^{\delta}(1-a) \mathrm{U}_{\ell}^{+} \mathrm{dy}_{\ell}^{+} .
$$

The results of performing the integration indicated in Equation (2-15) for the two void distributions are shown in Figure 1 and labeled Analysis $A$ and Analysis B, respectively. In summary, the Analysis $A$ results used Equations (2-3a), (2-7) and (2-12) in Equation (2-15), while Analysis B used Equations (2-4), (2-8), and (2-14).

Although Analysis B used the data input of the CISE film void distribution, Analysis $A$ fits the trend and position of the experimental $G_{f^{-}}^{+}$versus $\delta^{+}$results much better (within $10 \%$ of mean values). Both analyses predict. the film liquid flow rate better than the zero void analyses for the thicker films.

\section{ENTRAINMENT FRACTION
IN ADIABATIC, ANNULAR-DISPERSED TWO-PHASE FLOW}

There is a need to predict liquid entrainment rates along a developing two-phase, annular-dispersed flow. However, the phenomena of liquid entrainment and deposition are complicated. As a beginning, a description of the entrain- 
GEAP-10094

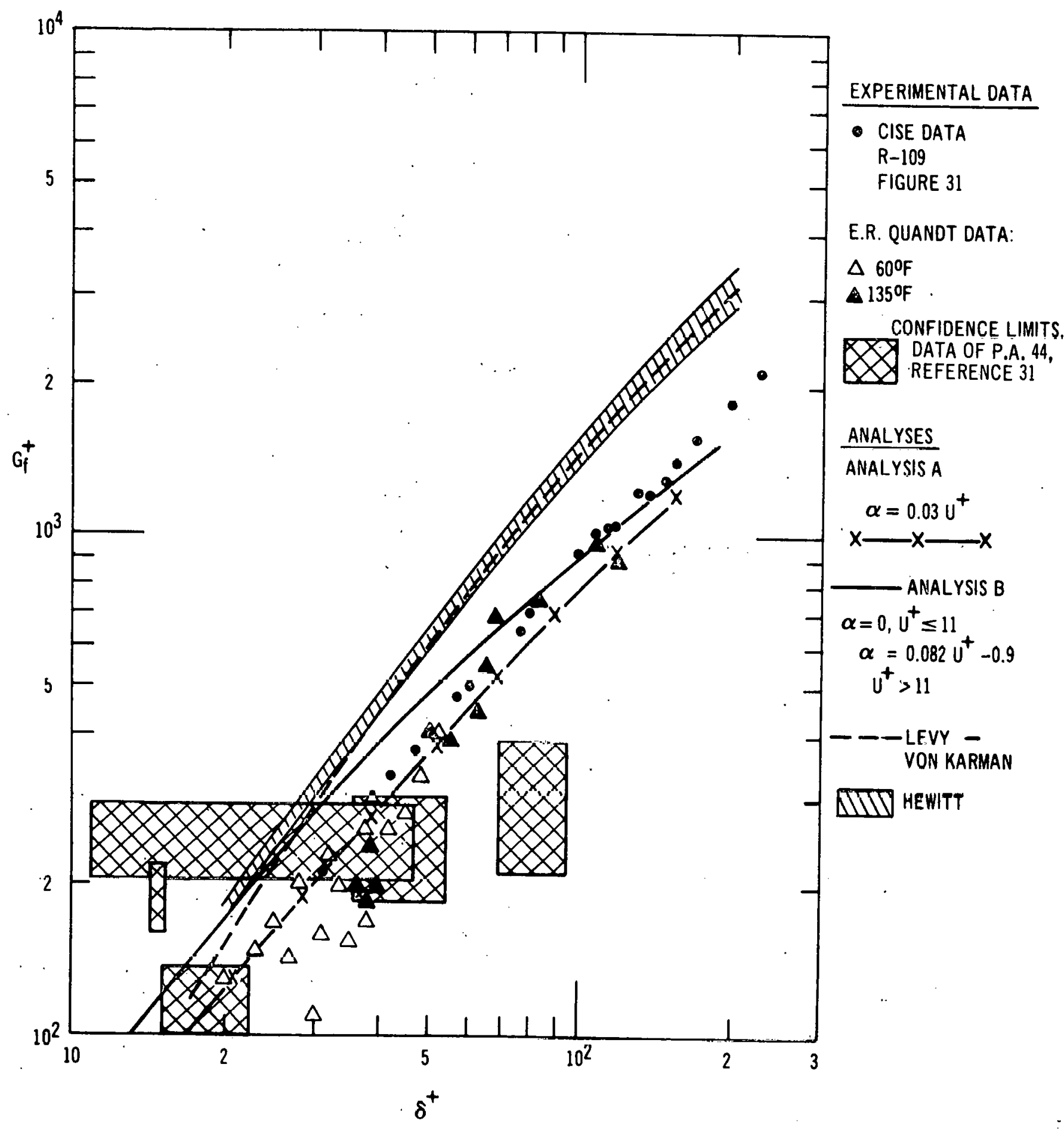

Figure 1. Dimensionless Film Liquid Flow Rate Versus Film Thickness 
ment fraction in the gas core for a fully-developed, adiabatic two-phase flow would be a stride forward. (By definition, an asymptotic or fully-developed, adiabatic two-phase flow is one where $\mathrm{d} \rho_{\mathrm{g}} / \mathrm{dz}$ is negligible and the entrainment fraction and $\mathrm{dP} / \mathrm{dz}$ remain essentially constant.)

Several investigators have suggested that large roll wave motions on the gas core-liquid film interface produce entrainment. For very thin films, these waves cease to exist and no further entrainment occurs. For fully-developed adiabatic conditions, the rate of entraining liquid into the air core equals the rate of depositing drops on the interface. Any characteristic length associated with the interface area must have little relevance in determining the asymptotic fraction of the core occupied by the entrained droplets.

Using the idea that the characteristic length is nondetermining, Paleev and Fillipovich ${ }^{21}$ proposed that

$$
\frac{\rho_{\mathrm{g}}}{\rho_{\ell}}\left(\frac{\mu_{\ell} \mathrm{G} g}{\rho_{\mathrm{g}} \sigma}\right)^{2}=\left(\frac{\mu_{\ell}^{2}}{\rho_{\ell} \sigma \mathrm{L}}\right)\left(\frac{\mathrm{G}_{\mathrm{g}}{ }^{2} \mathrm{~L}}{\rho_{\mathrm{g}} \sigma}\right)
$$

be the form for an entrainment fraction independent variable. Paleev and Fillipovich claim that the two dimensionless groups on the right side of Equation (3-1) are natural choices since they successfully correlate data from the interaction between a gas and liquid during nozzle spraying. (Though they do not reference any nozzle spraying work, the work of Hinze ${ }^{22}$ supports their statement.) Taking into account the entrained liquid in calculating the core density, they modify Equation (3-1) by substituting $\left(\rho_{\mathrm{g}} / \rho_{\ell}\right)(1+\mathrm{E} \mathrm{G} / \mathrm{G})$ for $\rho_{\mathrm{g}} / \rho_{\ell}$ to obtain

$$
\left(\frac{\rho_{g}}{\rho_{\ell}}\right)\left(1+E \frac{G_{\ell}}{G_{g}}\right)\left(\frac{G_{g} \mu_{\ell}}{\rho_{g} \sigma}\right)^{2}=I_{1} \text {. }
$$

Using data from several sources (21 and 23-26), they obtained

$$
1-E=0.985-0.44 \log _{10}\left[\Pi_{1} \times 10^{4}\right]
$$

as a fit through the mean of the data. For a given $\mathrm{II}_{1}$, most of the data points used by them fell within \pm 0.1 around this line, which is presented in Figure 2. The asymptotic (fully-developed) entrainment datum of the Gill, et al., ${ }^{6}$ developing flow is in excellent agreement with Equation (3.3), as shown in Figure 3.

The results of Minh and Huyghe ${ }^{27}$ for air-water and air-alcohol flows in round tubes are shown in Figure 3. These data alone examine the effects of cross-sectional area and different fluid properties on the entrainment fraction. These data were taken over a range of pressures from 1 to 8 atmospheres. The liquid film was sucked off through a uniform width slit around the tube perimeter. All the film liquid was assumed to be removed when an increase in slit width produced no increase in the flow rate of removed liquid. The entrainment fraction between $L / D=80$ and $L / D=300$ was reported unchanged, indicating a fullydeveloped condition. Apparently independent of Paleev and Fillipovich, they deduced a kinetic energy per unit volume parameter*

$$
\frac{G_{g}^{2}}{\rho_{g}}\left(1+E \frac{G_{\ell}}{G_{g}}\right)
$$

that correlates the area and density effects in their air-water data. As shown in Figure 3, their air-water and air-alcohol data are nearly superimposed when plotted in terms of $\Pi_{1}$.

Alia, et al., ${ }^{10}$ report film liquid flow rate data at $\mathrm{L} / \mathrm{D}=\mathbf{1 4 0}$ for argon-alcohol and argon-water flows. An isokinetic sampling scoop, forming a segment of an annulus, was traversed through the liquid film to obtain the total liquid flowing between the wall and some position $y$ in the film. The thickness of the liquid film was determined by a film conductance method. These results, shown in Figure 3 in terms of $\Pi_{1}$, are in basic agreement with the results of Minh and Huyghe, although the argon-alcohol results appear low. (Alia, et al., also present $E$ versus flow quality curves (Figure 32 of Reference 10) smoothed through their air-water data. Evaluating these curves in terms of $\Pi_{1}$. the results surround the Minh-Huyghe data.)

The air-water data of Cousins, et al., ${ }^{28}$ and Cousins and Hewitt ${ }^{29}$ for a $3 / 8$-inch-diameter acrylic resin tube were obtained by removing the wall liquid film through a porous section. The data ${ }^{29}$ were found to agree with the air-water data of Minh and Huyghe for $R_{f}>2000$. For $\operatorname{Re}_{f}<2000$, Cousins and Hewitt indicate that the data of Cousins, et al., fall above the Minh and Huyghe results and are Reynolds number dependent in the formulation. They found no length dependency on the data taken at $L / D>80$.

The air-water data of Cousins and Hewitt ${ }^{29}$ for a 1-1/4-inch-diameter copper tube, obtained by suntion through a porous sinter, were found to agree with the Paleev and Fillipovich Equation (3-3) for $\mathrm{Re}_{\mathrm{f}}>2000$ and $\mathrm{L} / \mathrm{D}>80$, as did the data of Collier and Hewitt ${ }^{25}$ for the same diameter pipe. They propose that the discrepancy between Equation (3-3) and the Minh and Huyghe data is due to a diameter effect (1-1/4:3/8). However, the data of Alia, et al., ${ }^{10}$ taken for a $2.5-\mathrm{cm}$-diameter tube agree with the Minh and Huyghe data and contradict the proposed diameter effect.

- Minh and Huyghe suggest that expression (3-4) be divided by $\bar{a}^{2}$. At high flow qualities $\bar{a} \rightarrow 1$, and the expression is then essentially unchanged. 


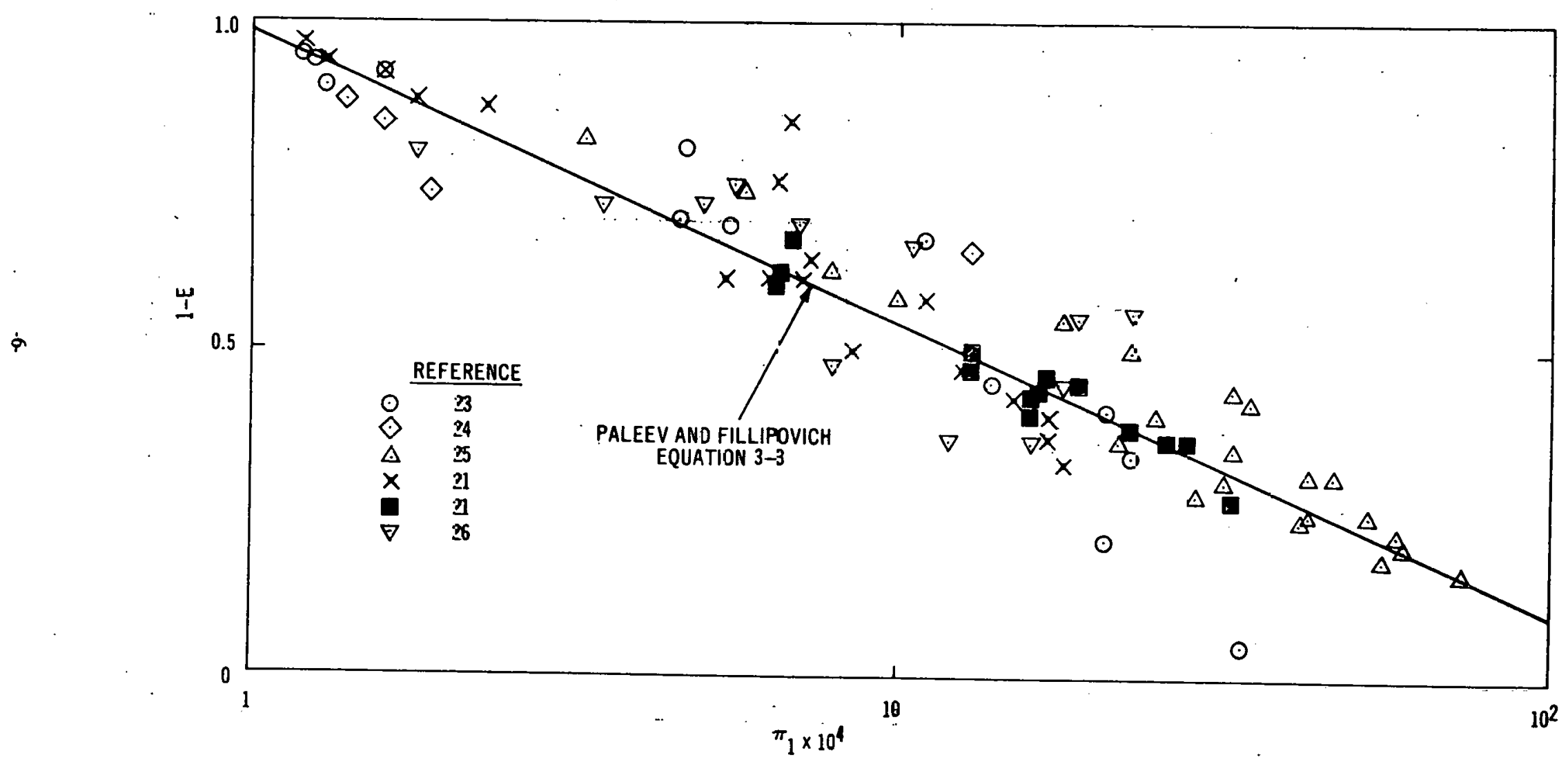

Figure 2. Data Presented by Paleev and Fillipovich 


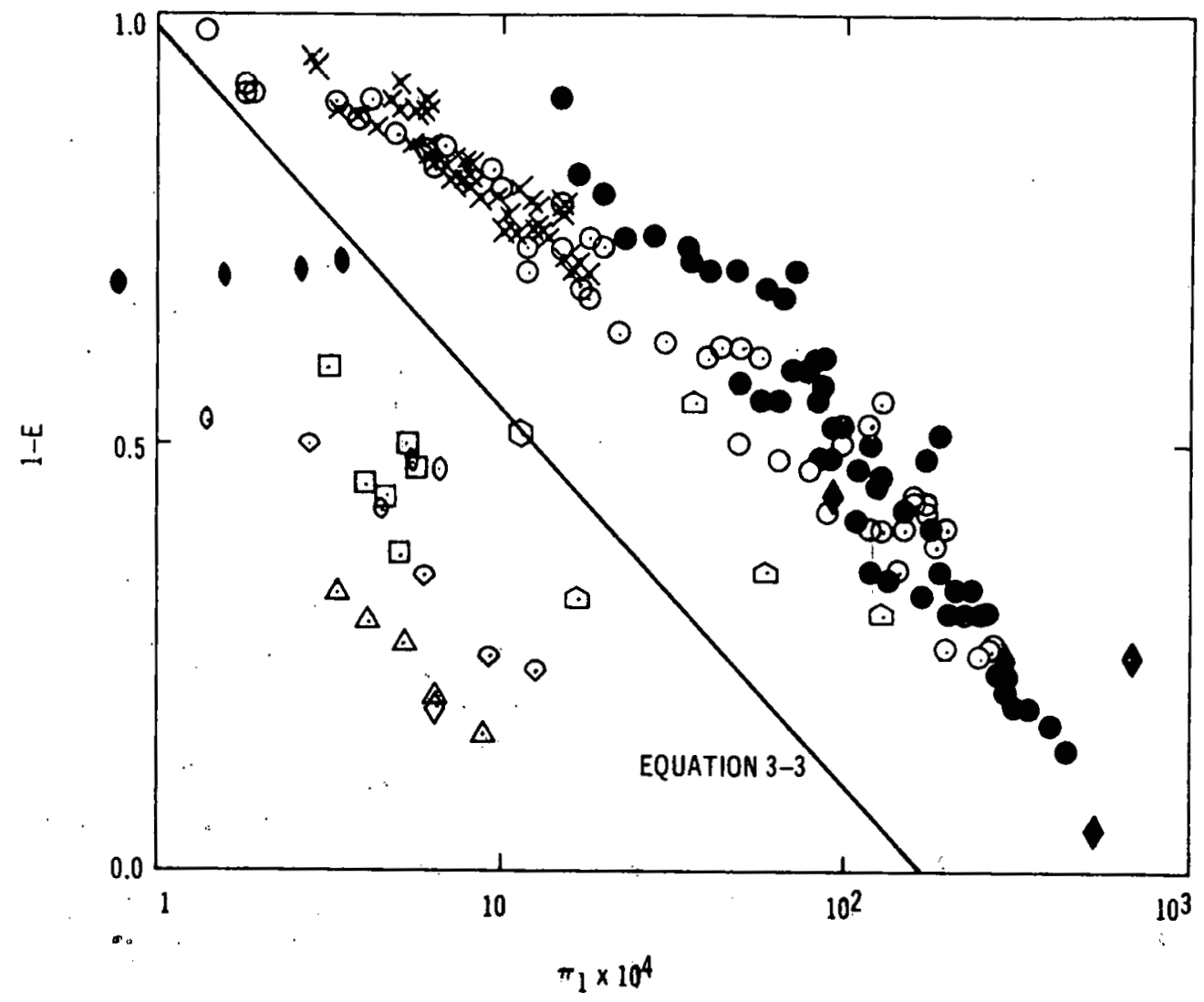

MINH AND HUYGHE (27)

$X$ WATER $\phi 12 \mathrm{~mm}$ diameter

O MATER $\phi .6 \mathrm{~mm}$ diameter.

- ALCOHOL $\phi 12 \mathrm{~mm}$ diameter

SINGH DATA(30)

O 1/2 inch SINTER

- linch SINTER

- 2-inch SINTER

Glb. HEWLTL ANO HITCHON(27)
CISE DATA ${ }^{(10), 2.5-\mathrm{cm} \text { DIAMETER }}$

$\left.\begin{array}{l}\square \text { ARGON - ALCOHOL } \\ \text { ARGON - WATER }\end{array}\right\}$ FILM SAMPLING

GE FILM DATA (AIR - WATER)(31)

$\triangle$ ROUND TUBE, l-inch diameter

$\square$ CONCENTRIC ANNULUS ) GF ROD AND TUBE,

$\odot$ ECCENTRIC ANNULUS $\left\{\begin{array}{l}\text { 1-inch-diameter TUBE, } \\ 0.5 \text {-inch-diameter ROD. }\end{array}\right.$

Figure 3. Further Entrainment Data 
The 1000-psia adiabatic steam-water round tube entrainment results of Singh, et al., ${ }^{31}$ are shown in Figure 3 in terms of $\Pi_{1}$. These data, obtained by suction through a porous sinter at $\mathrm{L} / \mathrm{D}=200$ from the entrance, fall below the correlation of Paleev and Fillipovich. Longer sinter lengths were used for higher total mass flow rates in an effort to catch all liquid in the film.

The air-water entrainment data of the P.A. 44 investigation $^{31}$ are presented in Figure 3 in terms of $\Pi_{1}$ for the round tube and the concentric and eccentric annulus. These data were taken under constant air flow ratevariable water flow rate conditions at essentially the same pressure and temperature by sucking off the film through 1-inch-long porous sinters 12 feet from the entrance. The flow is presumed to be fully developed, since isokinetic sampling profile measurements at 9 and 10.5 feet from the entrance were identical (within the uncertainty of the isokinetic sampling technique). There appear to be three general groupings from these data:

a. The data that are fairly well correlated by Equation (3-3). These data were taken by core liquid flow rate sampling techniques, with the exception of the Dowtherm and carbon dioxide data of Mondin and Huyghe who used the peripheral slit technique used by Minh and Huyghe, and some of the porous sinter method data of Cousins and Hewitt.

b. The slit and scoop data of Minh and Huyghe, and Alia, et al., and the 3/8-inch-diameter porous sinter data of Cousins, et al., and Cousins and Hewitt, that fall above Equation (3 3).

c. The porous sinter data of Singh, et al., and the present investigation, that fall below Equation (3-3).

At first glance, it would appear that $\mathrm{E}$ is either not a unique function of $\Pi_{1}$, or improper properties are contained in $\Pi_{1}$. However, each set of these data taken on a given apparatus with a given measurement technique, is self-consistent with the $E$ versus $\Pi_{1}$ formulation. The data of Minh and Huyghe show the effect of changing all variables in $\Pi_{1}$, although $\mu_{\ell}$ and $\rho_{\ell}$ for water and alcohol are nearly the same. The data of Alia, et al., show mainly the effect of the surface tension for argon-water and argonalcohol flows. With the exception of the Mondin and Huyghe work, the remaining investigations used water as the working liquid.

The data of Steen ${ }^{32}$ are plotted in Figure 4. These data, taken at $L / D>90$ for air-silicone, air-ethylene glycol, and air-water flows, examine the effect of different fluid properties with substantial variations in $\mu_{\ell}$. The air-water data agree with the data of Minh and Huyghe, but the remaining data fail to correlate with $\Pi_{1}$.Only in Steen's experiments was $\mu_{\ell}$ varied substantially so that the liquid viscosity dependence could be examined. Because these data indicate a higher liquid viscosity results in higher $\Pi_{1}$ but lower $\mathrm{E}$, an empirical viscosity ratio factor to correct
$\Pi_{1}$ was derived from the silicone data $\left(9<\operatorname{Re}_{\mathrm{f}}<1100\right)$. (The silicones have essentially the same $\rho_{\ell}$ and $\sigma$, but $\mu_{\ell}$ varies from 5 to 100 centipoises.) This viscosity factor is

$$
\left(\frac{\mu_{\mathrm{g}}}{\mu_{l}}\right)^{11 / 5}
$$

normalizing on the gas viscosity, which varies little in all these data. Hence,

$$
\begin{aligned}
\Pi_{3} & =\Pi_{1}\left(\frac{\mu_{\mathrm{g}}}{\mu_{\ell}}\right)^{11 / 5} . \\
& =\left(\frac{\rho_{\mathrm{g}}}{\rho_{\ell}}\right)\left(1+\mathrm{E} \frac{\mathrm{G}_{\ell}}{\mathrm{G}_{\mathrm{g}}}\right)\left(\frac{\mathrm{G}_{\mathrm{g}} \mu_{\mathrm{g}}}{\rho_{\mathrm{g}} \sigma}\right)^{2}\left(\frac{\mu_{\mathrm{g}}}{\mu_{\ell}}\right)^{1 / 5}
\end{aligned}
$$

should correlate the effect of liquid viscosity as well as the effect of properties correlated by $\Pi_{1}$. The ? vameter $\Pi_{3}$ is in substantial agreement with Steen's parameter $\Pi_{2}$, since

$$
\Pi_{3}=\Pi_{2}^{2}\left(1+E \frac{G_{\ell}}{G_{g}}\right)\left(\frac{\mu_{g}}{\mu_{\ell}}\right)^{1 / 5}
$$

where

$$
\Pi_{2}=\frac{\mathrm{G}_{\mathrm{g}} \mu_{\mathrm{g}}}{\rho_{\mathrm{g}} \sigma}\left(\frac{\rho_{\mathrm{g}}}{\rho_{\ell}}\right)^{1 / 2}
$$

and the liquid viscosity plays a lesser role than the gas visiusity.

As shown in Figure 5, Steen's air-water and air-ethylene glycol data are nearly superimposed on the air-silicone data when plotted in terms of $\Pi_{3}$. These data correlate with the Minh and Huyghe, and Alia, et al., data which, in turn, are better correlated by $\Pi_{3}$ than $\Pi_{1}$, as shown in Figure 6 . The equations

$$
\begin{aligned}
& 1-E=0.819-0.112 \log _{10}\left|\Pi_{3} \times 10^{7}\right| \\
& \text { for } \Pi_{3}<4.5 \times 10^{7}, \text { and } \\
& 1-E=0.966-0.210 \log _{10}\left|1 \Pi_{3} \times 10^{i}\right|
\end{aligned}
$$

for $\Pi_{3}>4.5 \times 1 \sigma^{7}$ fit these data, as shown in Figures 5 and 6 .

The data of Singh, et al., and the present investigation do not correlate with the other data in terms of $\Pi_{3}$. Likewise, the ambient temperature air-water data that correlate with Equation (3-3) are merely shifted by nearly the same viscosity ratio factor and will not correlate with the Steen, Minh and Huyghe, and Alia; et al., data.

In conclusion, there is considerable evidence that the $\mathrm{E}$ versus $\Pi_{3}$ formulation contains proper parameters for fully developed adiabatic two-phase annular dispersed flows. Although all the results from these several investigations do not agree, the results from a given apparatus with a given 


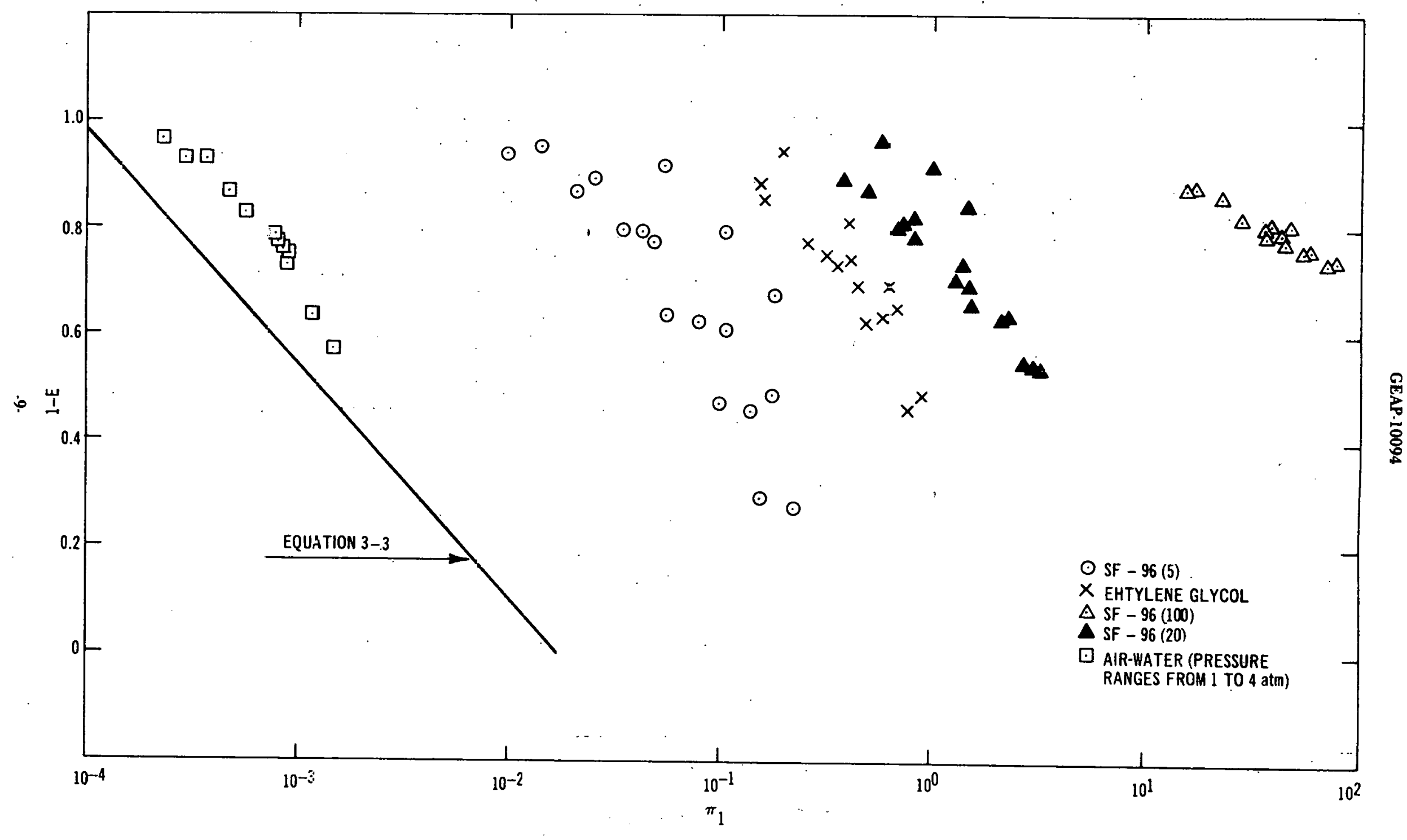

Figure 4. Data of Steen (See Ref. 32) 


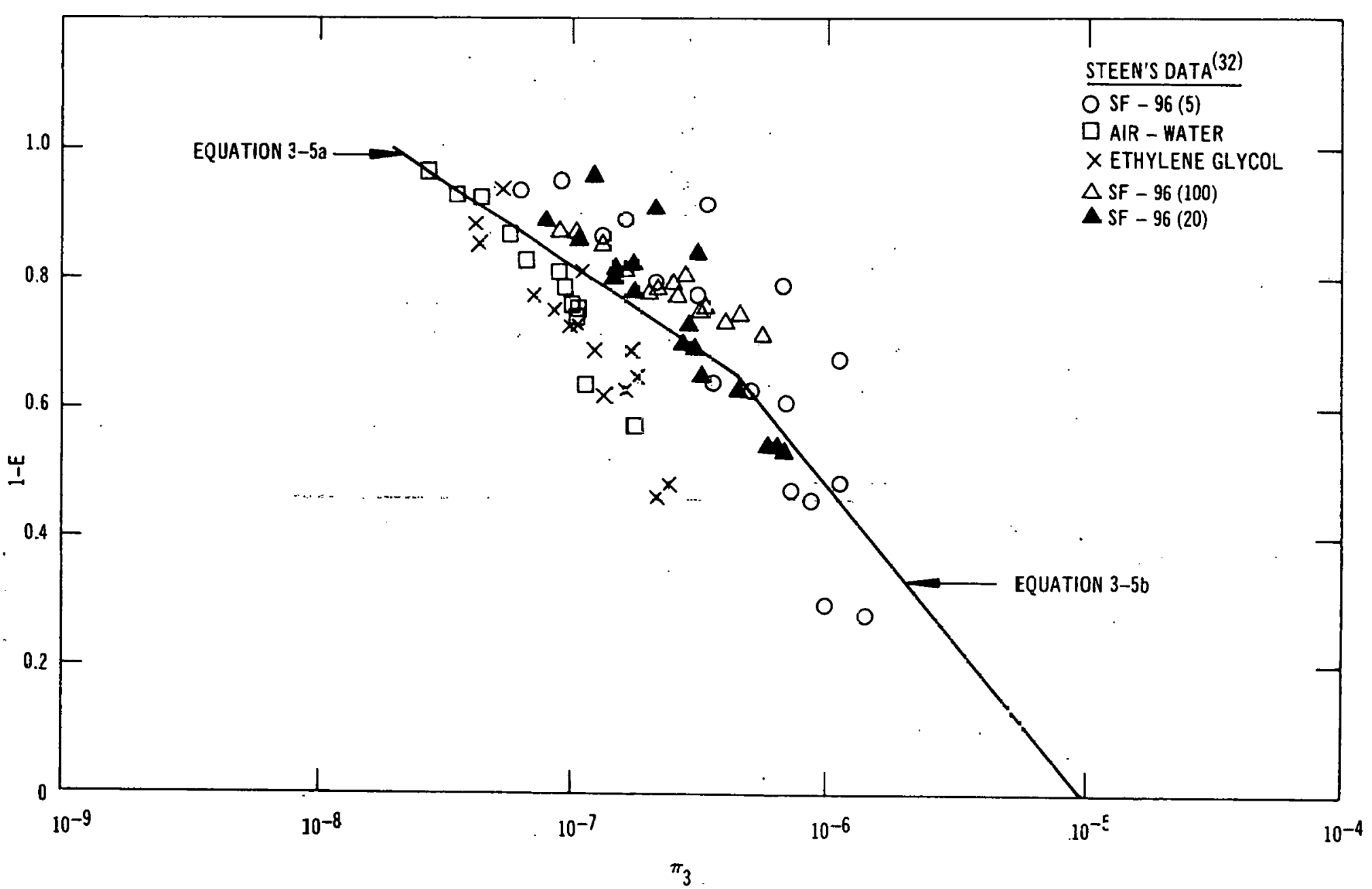

Figure 5. Stzent's Entrainment Data in Terms of $\pi_{3}$ 


\section{SINGH DATA(30)}

V/2-inch SINTER $\varnothing$ 1-inch SINTER 2-inch SINTER

P.A. 44 DATA (31) ROUNND TUBE $\triangle$ CONCENTRIC ANNULUS ECCENTR'C ANNULUS

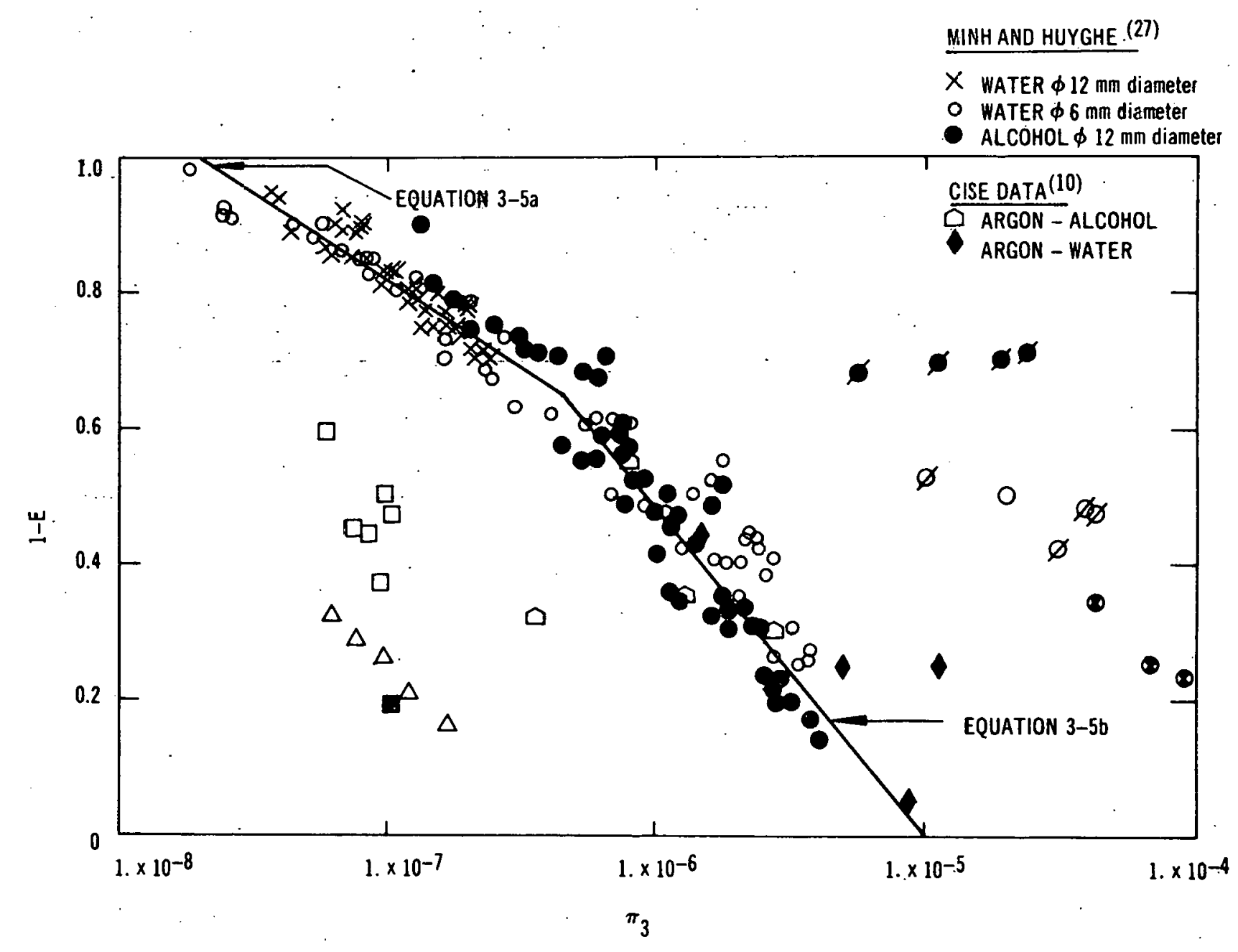

Figure 6. Entrainment in Terms of $\pi_{3}$ 
measurement technique are self-consistent with the $E$ versus $\Pi_{3}$ formulation when parameters contained in $\Pi_{3}$ are varicd.

It is difficult to assess which measurement technique is best since no investigation has covered obtaining the same entrainment data by more than one method. Steen ${ }^{32}$ has shown that the one radial position core liquid sampling technique he used has shortcomings for obtaining high entrainment data, the results being probe position and size dependent. However, because Steen used the same size probe at the same radial location for the air-silicone data used here, it is felt that the qualitative property dependence shown by his data is valid. The spacer results of Alia, et al., ${ }^{33}$ indicate that small protrusions from the walls can produce further entrainments. This could be the case for the data of the present investigation, since slight misalignment of the void fraction quick-closing valves upstream of the porous sinters could have produced a low film flow rate. as the data indicate. As pointed out in Reference 31 , there is some uncertainty in interpreting the flow rate results from the porous sinter method. The isokinetic scoop and peripheral slit techniques data are consistent, and probably disturb the flow the least. Hence, it is concluded that some of the data discussed here are rig and measurement technique dependent. In light of this discussion, it is also concluded that the data of Minh and Huyghe and Alia, et al., are likely the best quantitatively.

More careful fully-developed flow entrainment experiments with careful measurement of all flow structure quantities $(\mathrm{dP} / \mathrm{dx}, a$, film thickness, wave structure, film liquid flow rate, and isokinetic sampling to obtain air-water velocity profiles) at several axial positions would indicate whether the flow was fully devcloped and would help resolve the proper $\mathrm{E}$ versus $\Pi_{3}$ rclationship, as well as provide more information about the entrainment phenomena.

\section{CORE GAS LINEAR VELOCITY PROFILES}

In fully-developed, turbulent, single-phase flow in a round tube, a definite core $(y / R \gtrsim 0.05)$ velocity profile similarity has been established; namely,

where

$$
\frac{\mathrm{U}_{\mathrm{Gg}_{\mathrm{g}}}-\mathrm{U}_{\mathrm{g}}}{\mathrm{U}_{r_{\mathrm{g}}}}=\mathrm{f}(\mathrm{y} / \mathrm{R})
$$

$$
f(y / R) \sim \ln |y / R|
$$

as the wall is approached ${ }^{35}$. One would expect that for a low entrained liquid annular two-phase flow, the formulation of Equation (4-1) may well hold for the gas linear velocity

$$
\mathrm{U}_{\mathrm{g}}=\mathrm{G}_{\mathrm{g}} / \rho_{\mathrm{g}} a
$$

The gas linear velocity results of the present. investigation are shown in Figure 7 to be substantially independent of mean flow quality within the scatter of the results. The experimental gas linear velocity results of Alia, et al., ${ }^{10}$ are shown in Figure 8 for fully-developed annular dispersed flows. These sets of data are in close agreement for $y / R>$ 0.1. (All these data were obtained by isokinetic sampling and impact pressures. Near the wall, the isokinetic probe interferes with the liquid film so that the isokinetic sampling results from both investigations for $y / R<0.1$ are not completely reliable.) Apparently, the constant local slip ratio assumption of Alia, et al.; in reducing their data produces nearly the same results as obtained in the present investigation using a variable local slip ratio assumption. ${ }^{36}$
Also shown in Figures 7 and 8 are the single-phase. turbulent flow results of $\operatorname{Laufer}^{37}$ for the pipe, and Wieghardt ${ }^{38}$ for the flat. plate. These single-phaoc rcsults have been theoretically described by ${ }^{38}$

$$
f(y / R)=-\frac{1}{0.4} \ln |y / R|+g(y / R)
$$

for large Reynolds numbers. ${ }^{34}$ Note that Equation (4-3) is composed of a logarithmic term and a large eddy correction term, the latter being slightly different for the pipe and the flat plate ${ }^{34}$. The gas linear velocity results appear to fall between the pipe and flat plate results. This is not suprising since the single-phase pipe flow is constrained by the walls, while the flat-plate flow can propagate into the freestream. The two-phase annular flow is constrained within the pipe, but the interface between the liquid film and the core remains free. Hence, the large eddy structure of the twophase annular sorc flow is likely tu be a combination of pipe and flat-plate characteristics, as indicated by the data.

Alia, et al., fitted

$$
f(y / K)=\frac{1}{K} \ln |y / R|
$$

to their data for $y / R>0.1$, obtaining $K=0.3$. They contended that the liquid droplets decreased the turbulence level in the core since single-phase flows were known to produce $K=0.4$. It should be noted that in single-phase flow, the region $y / R>0.1$ is also described by an additive large eddy turbulence furction such as the one contained in Equation (4-3). Thus, this interpretation of the effect of droplets on turbulence level need not hold to explain the 
RUN SYMBOL QUALITY

$\begin{array}{ccc}5 & \odot & 0.4784 \\ 6 & \triangle & 0.6200 \\ \text { TM03 } & \diamond & 0.2078 \\ T 02 & \bullet & 0.2923 \\ T M 01 & \Delta & 0.3580 \\ 4 & \bullet & 0.1104\end{array}$

$\bar{\varphi}$

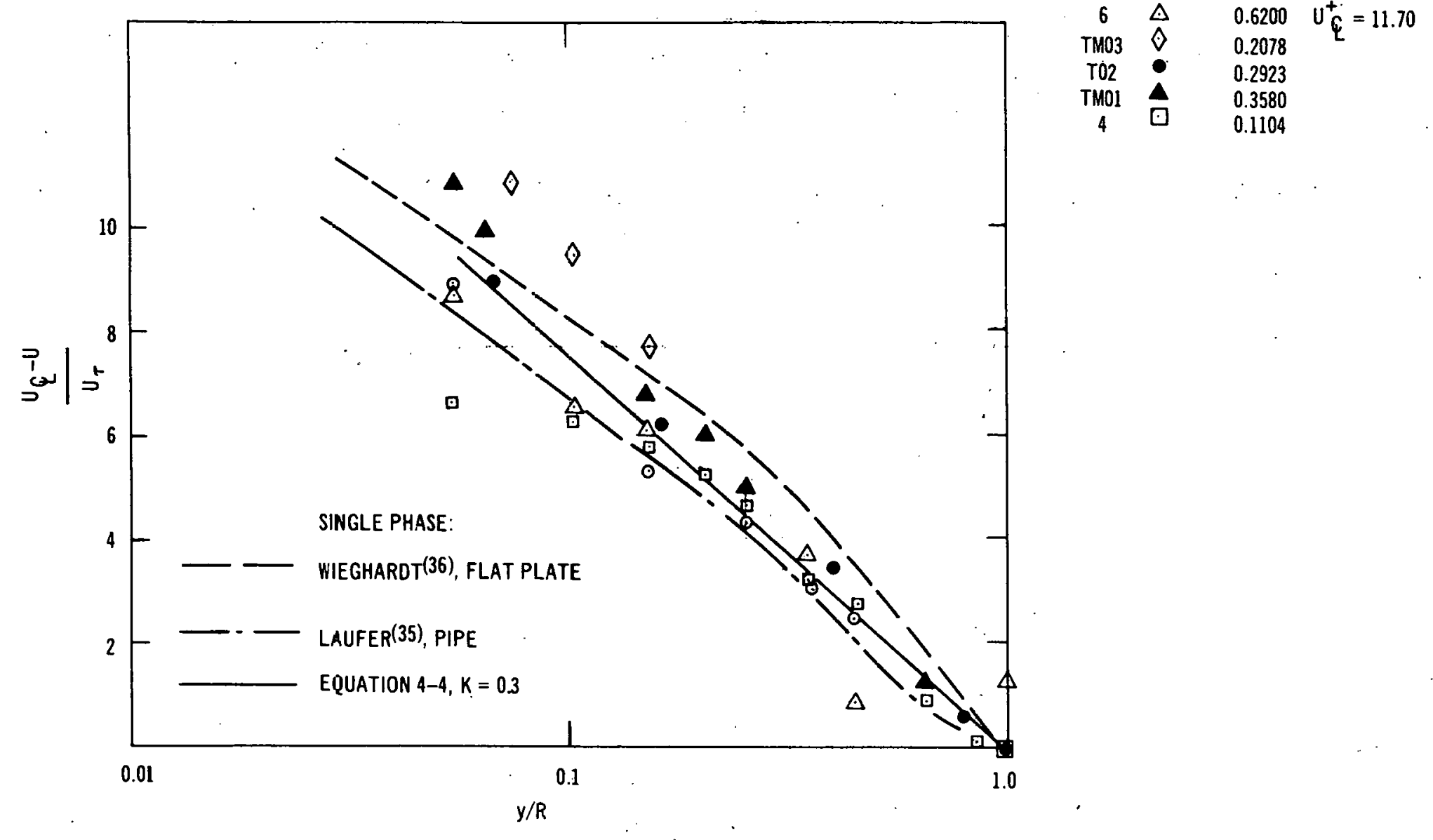

Figure 7. Core Gas Linear Velocity Data of Schraub, Simpson, and Janssen (See Ref. 31) 


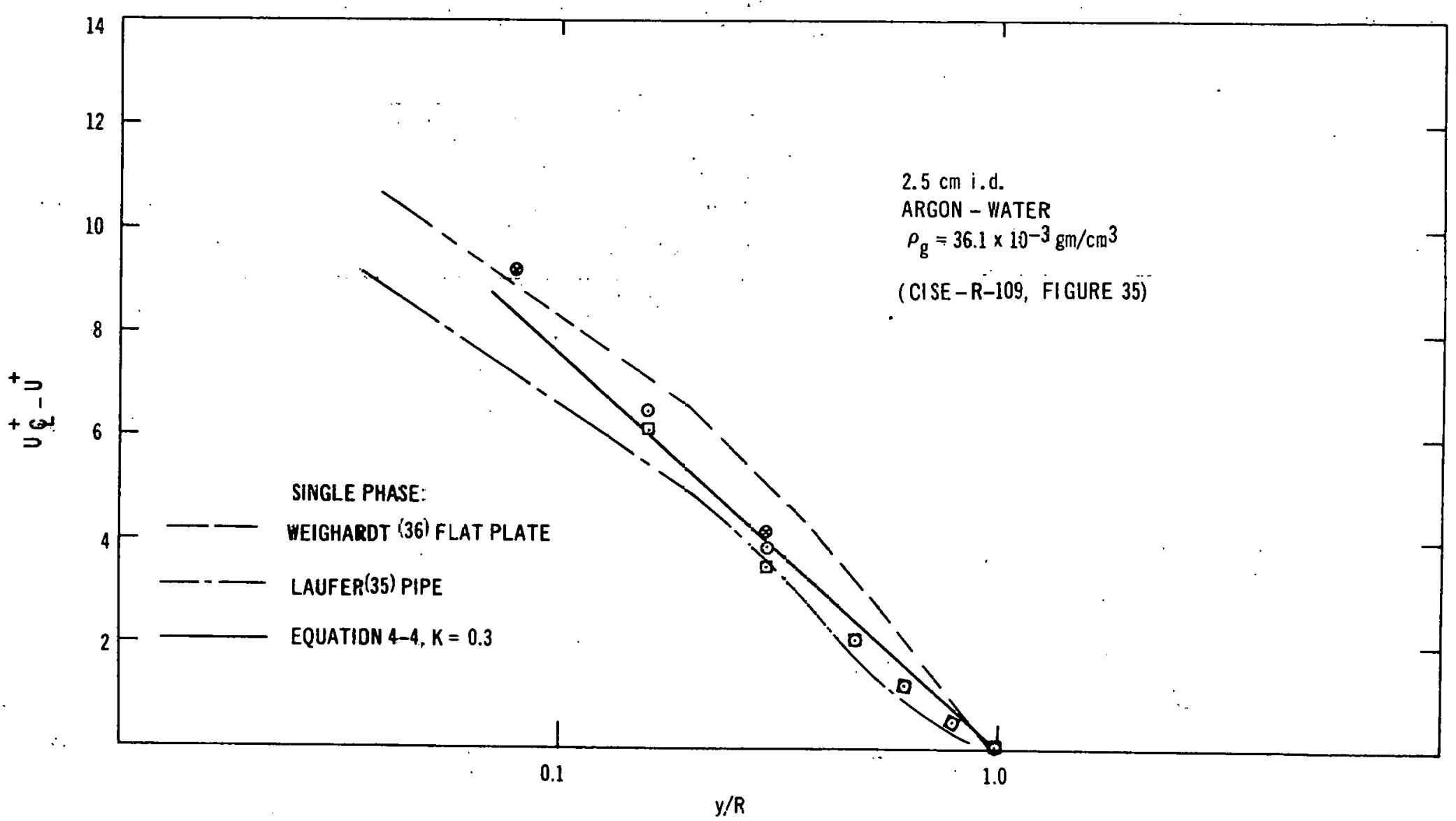

Figure 8. Data of Alia, Et al. (See Ref. 10) 
gas linear velocity profile. Equation (4-3), with a hybrid large eddy term from the pipe and flat-plate single-phase flows, appears to be applicable to the gas linear velocity profiles for annular-dispersed flows with qualities greater than $11 \%$.

\section{LIQUID VOLUMETRIC DISTRIBUTION IN THE GAS CORE}

In a fully-developed, annular-dispersed two-phase flow, one would expect the droplet volumetric concentration in the gas core to be uniform, providing droplet gradient diffusion is the only mechanism of transport. Some sampling data support this view, ${ }^{38}$ while other data $^{10} 3138$ show concave upward 1-a profiles as a function of $r$. The latter group of data indicates that another mechanism, in addition to gradient diffusion, plays an important transport role.

Turbulent drift of droplets toward the tube walls has been observed to be a deposition mechanism in aerosol research $^{39}$. Sternling, as cited by Cousins and Hewitt ${ }^{38}$, also suggests turbulent drift as a possible mechanism of droplet deposition. Sternling contends that droplets near the centerline are likely to encounter a large eddy and be preferentially thrown toward the wall. The gradient diffusion mechanism would tend to even out the concentration.

Thus, Cousins and Hewitt ${ }^{38}$ wrote:

$$
\ddot{Q}_{D}^{\prime \prime}=V_{r}(1-a)-\epsilon_{D} \frac{d(1-a)}{d r}
$$

where $V_{r}$ is the turbulent drift velocity, $Q_{D}$ is net radial liquid volumetric flux, and $\epsilon_{\mathrm{D}}$ is the turbulent gradient diffusion coefficient.

In a fully-developed flow; $\ddot{Q}_{D}$ is zero, and

$$
\frac{V_{\mathrm{r}}}{\epsilon_{\mathrm{D}}} \mathrm{dr}=\frac{1}{(1-a)} \mathrm{d}(1-a) \text {. }
$$

Integrating from the centerline to radius $r$ yields

$$
\int_{G}^{r} \frac{V_{r}}{\epsilon_{D}} d r=\ln \left|\frac{(1-a)}{(1-a)_{G}}\right| .
$$

If one sets the eddy diffusion and momentum coefficients equal and uses Laufer's ${ }^{35}$ pipe results, then

$$
\epsilon_{\mathrm{M}}=\epsilon_{\mathrm{D}}=0.07 \mathrm{U}_{\tau \mathrm{g}} \mathrm{R}
$$

for $\mathrm{r} / \mathrm{R}<0.8$. Sehmel ${ }^{39}$ suggests that $V_{\mathrm{r}} \sim \mathrm{U}_{\tau}$. Requiring a fit of the form $V_{r} \sim(r / R){ }^{n} U_{\tau}$, one finds (see Figure 9)

$$
V_{\mathrm{r}}=\frac{1}{2}(\mathrm{r} / \mathrm{R})^{2} \mathrm{U}_{\tau}
$$

and the resulting equation

$$
\frac{1}{0.42}(r / R)^{3}=\ln \left|\frac{(1-a)}{(1-a)_{\Phi}}\right|
$$

to fit roughly the isokinetic sampling results of Reference 31. The data of Reference 38 show (see Figure 10) less curvature, the higher the quality. These data indicate that the droplet volumetric profile is not a unique function of quality.

The 0.4784 quality run results shown in Figure 9 indicate the dependence of sampling probe results on the data reduction scheme. Data reduced by the British homogeneous method ${ }^{6}$ (unity local slip ratio, void weighted density) show a rather flat profile, while the same data reduced by the isokinetic sampling equations of Schraub $^{18}$ show more profile curvature. (As pointed out in Reference 31, and in Figure 11 there is little difference in the local air linear velocity and local quality results obtained by these two reduction schemes. There is more difference in the $(1-a)$ results.

Thus, while the rate Equation (5-1) may be applicable, there is no a priori basis for Equation (5-4). To predict the profile shape, one must have $V_{\mathbf{r}}$ and $\epsilon_{\mathrm{D}}$ expressed as a function of quality as well as position. Alia, et al., ${ }^{10}$ indicate that the void profile flattens with increasing flow rates, increasing gas density at constant volume flow rate and decreasing surface tension. Hence, $V_{r}$ and $\epsilon_{D}$ must also be a function of fluid properties. In addition, the sampling data void results are dependent upon the data reduction scheme, making the deduction of $\epsilon_{\mathrm{D}}$ and $V_{\mathrm{r}}$ from sampling data uncertain.

The results of Figure 9 indicate that when a unity local slip ratio is used in reducing the data, the assumption of a constant core droplet volumetric concentration is not bad. This assumption is not only useful, in view of the uncertainties mentioned above, by eliminating the core $a$ variation, but it also eliminates the need to know the local slip ratio variation. 


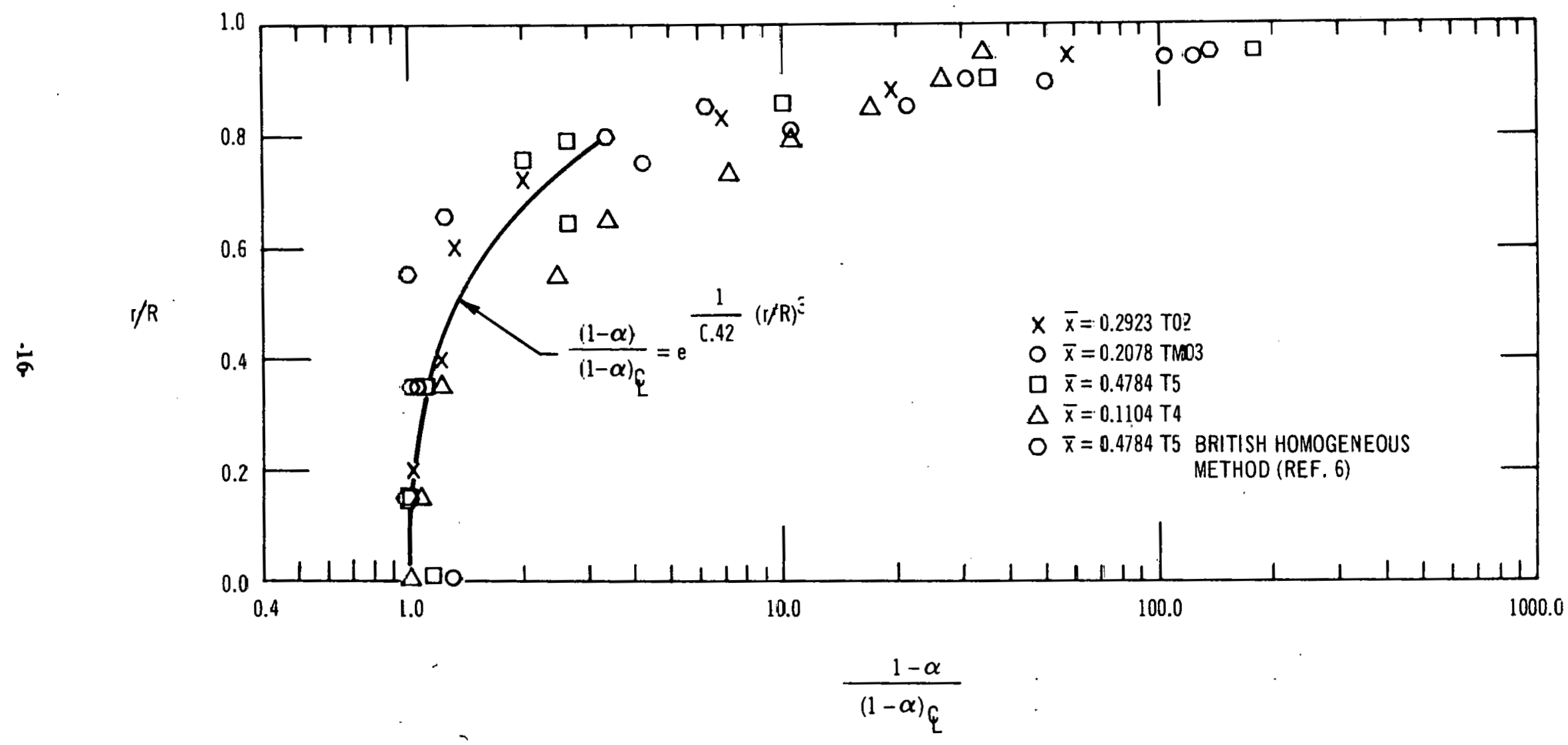




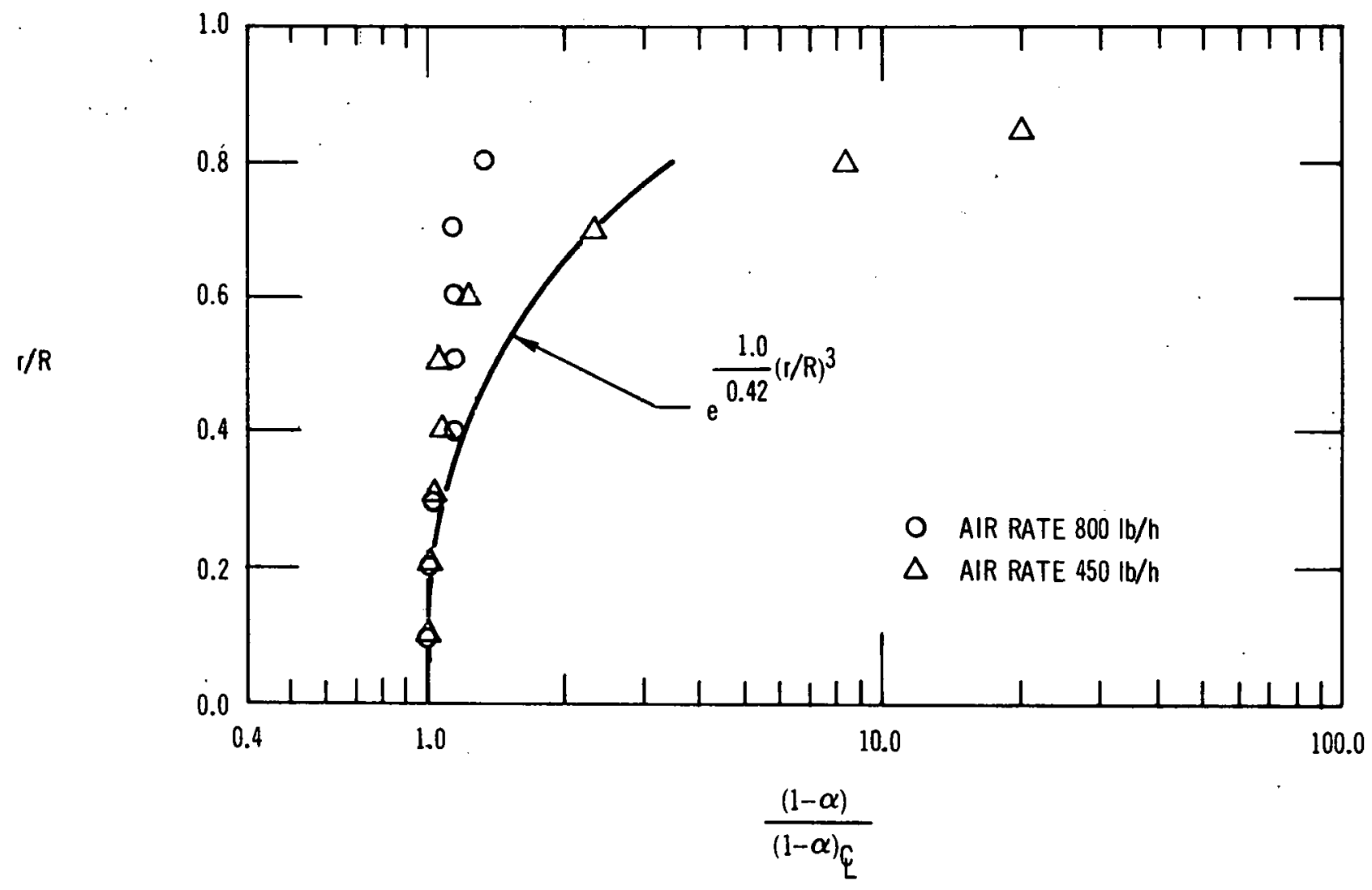




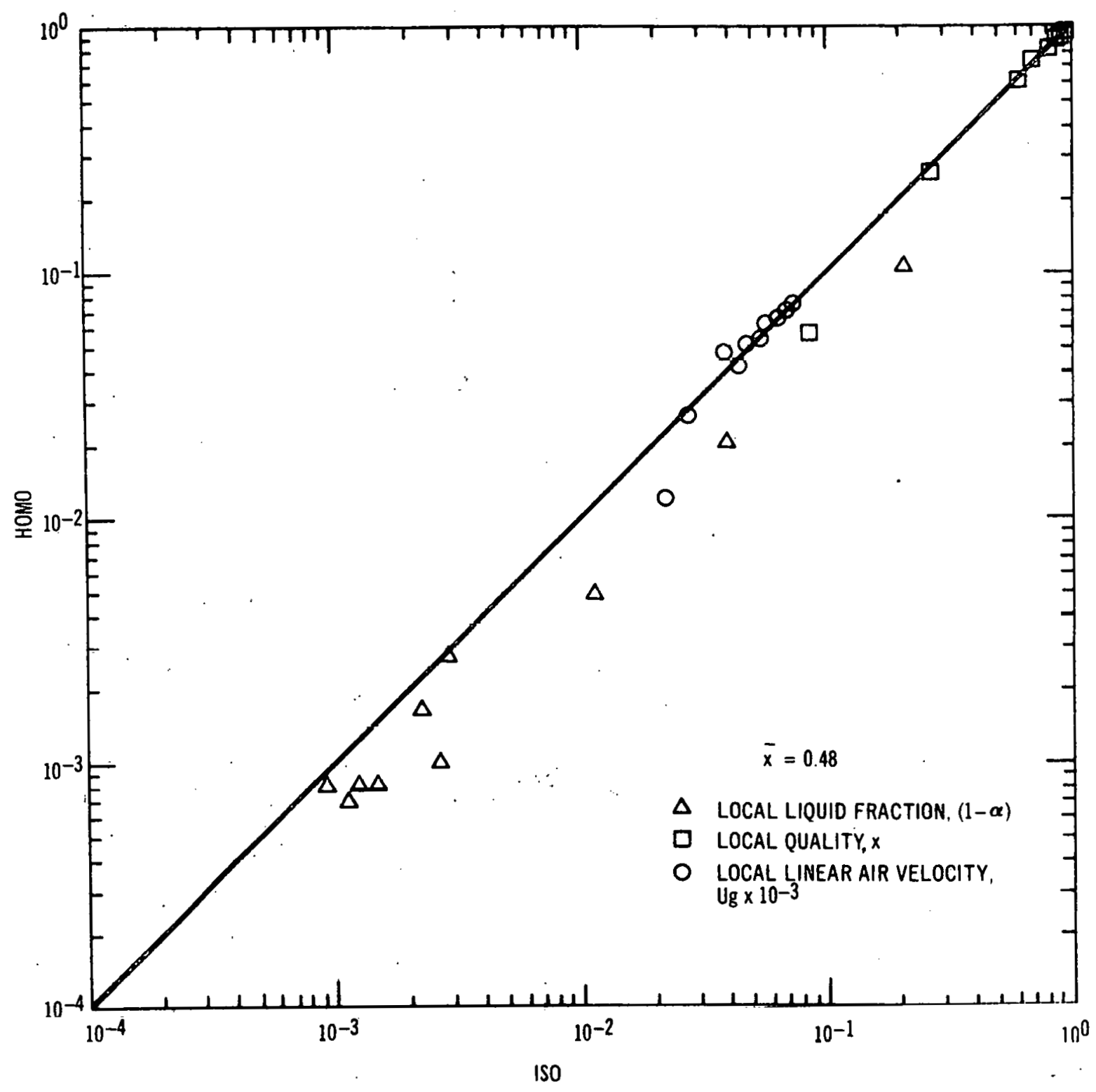

Figure 11. Comparison of Data Reduced by the lsokinetic and British Homugeneous Methods 


\section{THE PREDICTION OF PRESSURE DROP, MEAN VOID FRACTION, AND FILM THICKNESS}

The second objective of demonstrating the inter-model consistency of these several models was attained by comparing calculated pressure drop, mean void fraction, and film thickness results with experimental results. A schematic diagram of the calculation steps is shown in Figure 12.

In the present approach, one must first start with an entrainment fraction model such as one derived in Section 3 , and the given input information, $\dot{\mathrm{W}}_{\ell}, \dot{\mathrm{W}}_{g}, \mathrm{R}$, and fluid properties. With this information one uses Equation (6-1) to determine $\mathrm{G}^{+}$:

$$
\mathrm{G}^{+}=\frac{\dot{\mathrm{W}}_{\ell \mathrm{f}}}{2 \Pi \mathrm{R} \mu_{\ell}},
$$

where $\dot{W}_{\ell f}$ is the film liquid flow rate in the film modol of Section 2 . The film gas flow rate, $\dot{W}_{\mathrm{gf}}$, the dimensionless film thickness $\delta^{+}$or $y_{\ell j}^{+}$, and the dimensionless film-core mean interface velocity $\mathrm{U}_{\ell_{i}}^{+}$are determined from the film model.

One now can calculate the mean core void fraction $\bar{a}_{\text {. }}$ The liquid flow rate in the core $\dot{\mathrm{W}}_{\ell c}$ is determined from $\dot{\mathrm{W}}_{\ell}$ and the entrainment fraction $E . \dot{W}_{g c}$, the gas flow rate in the core, is determined by substracting $\dot{\mathrm{W}}_{\mathrm{gf}}$ from $\dot{\mathrm{W}}_{\mathrm{g}}$. As noted in Section 5, a constant core void with a local slip ratio of $l$ is not in bad agreement with data reduced, assuming a local slip ratio of 1 . Hence, with local slip ratio of 1 , one obtains

$$
\bar{a}_{\mathrm{i}}=\frac{1}{\left(1+\frac{\rho_{\mathrm{g}}}{\rho_{\ell}} \frac{\dot{\mathrm{W}}_{\ell \mathrm{C}}}{\dot{\mathrm{W}}_{\mathrm{gc}}}\right)} .
$$

Also, from the film model one can calculate $\mathrm{y}_{\mathrm{gi}}^{+}$and $\mathrm{U}_{\mathrm{gi}}^{+}$ of the core-film interface from $\mathrm{U}_{\ell_{i}}^{+}$and $\mathrm{y}_{\ell_{i}}^{+}$; i.e.,

$$
\left.\begin{array}{l}
\mathrm{y}_{\mathrm{gi}}^{+}=\mathrm{y}_{\mathrm{li}}^{+}\left(\begin{array}{c}
\nu_{\ell} \\
\cdots \\
\nu_{\mathrm{g}}
\end{array}\right)\left(\begin{array}{c}
\rho_{\ell} \\
\cdots \\
\rho_{\mathrm{g}}
\end{array}\right)^{1 / 2} \\
\mathrm{U}_{\mathrm{gi}}^{+}=\mathrm{U}_{\mathrm{li}}^{+}\left(\frac{\rho_{\mathrm{g}}}{\rho_{\mathrm{l}}}\right)^{1 / 2}
\end{array}\right\}
$$

which satisfies the kinematic condition that the mean quantities $U=U_{i}$ and $y=y_{i}$ at the mean core-film interface. Using the logarithmic gas linear velocity profile $(g(y / R) \rightarrow 0$ as $y / R \rightarrow 0$ ),

$$
U_{g}^{+}=\frac{1}{K} \ln \left(\frac{y_{g}^{+}}{y_{g i}^{+}}\right)+U_{g i}^{+}-g(y / R) .
$$

One can now obtain a value for $\mathrm{U}_{\tau g}$, the shear velocity based on gas properties, by a gas mass balance for the core:

$$
\mathrm{U}_{\tau \mathrm{g}}=\frac{2 \Pi \rho_{\mathrm{g}} \nu_{\mathrm{g}}^{2} \bar{a}_{\mathrm{c}}}{\dot{\mathrm{W}}_{\mathrm{g}}} \int_{\mathrm{y}_{\mathrm{gi}}^{+}}^{\mathrm{R}^{+}} \mathrm{U}_{\mathrm{g}}^{+}\left(\mathrm{R}_{\mathrm{g}}^{+} \cdot \mathrm{y}_{\mathrm{g}}^{+}\right) \mathrm{dy}_{\mathrm{g}}^{+},
$$

where

$$
\begin{aligned}
& -\int_{y_{\mathrm{gi}}^{+}}^{\mathrm{R}^{+}} \mathrm{U}_{\mathrm{g}}^{+}\left(\mathrm{R}_{\mathrm{g}}^{+}-\mathrm{y}_{\mathrm{g}}^{+}\right) \mathrm{dy} \mathrm{g}_{\mathrm{g}}^{+} \\
& =\frac{1}{\mathrm{~K}}\left\{\mathrm{R}_{\mathrm{g}}^{\prime^{2}}\left[\frac{-8 \mathrm{n}}{2}\left(\frac{\mathrm{R}_{\mathrm{g}}^{+}}{\mathrm{y}_{\mathrm{gi}}}\right)+\frac{3}{4}\right]+\frac{\mathrm{y}_{\mathrm{gi}}^{+^{2}}}{4} \cdot \mathrm{R}_{\mathrm{g}}^{+} \mathrm{y}_{\mathrm{gi}}^{+}\right\} \\
& +\frac{\mathrm{y}_{\mathrm{gi}}^{+^{2}} \mathrm{U}_{\mathrm{gi}}^{+}}{2}\left[\left(\frac{\mathrm{R}_{\mathrm{g}}^{+}}{\mathrm{y}_{\mathrm{gi}}^{+}}\right)^{2}-1\right]-\mathrm{R}_{\mathrm{g}}^{+} \mathrm{y}_{\mathrm{gi}}^{+} \mathrm{U}_{\mathrm{gi}}^{+}\left[\frac{\mathrm{R}_{\mathrm{g}}^{+}}{\mathrm{y}_{\mathrm{gi}}^{+}} \cdot \mathrm{l}\right] \\
& -\int_{y_{g i}^{+}}^{R^{+}} g\left(y_{g}^{+} / R_{g}^{+}\right) y_{g}^{+} d y_{g}^{+}+R_{g}^{+} \int_{y_{g i}^{+}}^{R^{+}} g\left(y_{g}^{+} / R^{+}\right) d y_{g}^{+} .
\end{aligned}
$$




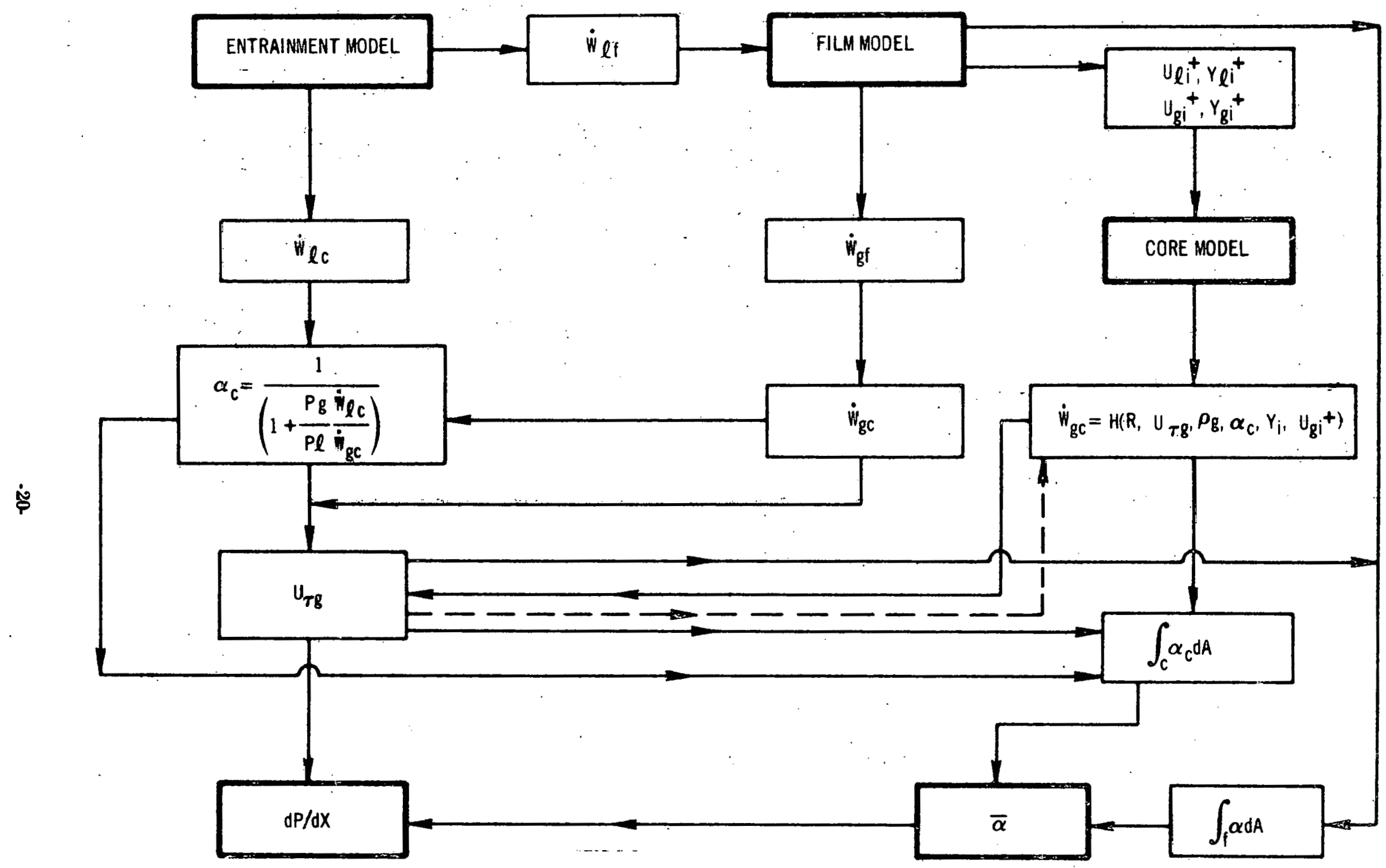

Figure 12 Schematic Diagram of Pressure Drop and Void Fraction Computation Method 
If we use Hinze's ${ }^{34} g(y / R)$ function for a pipe (p. 518 , Figure 7-30) approximated by

$$
\begin{aligned}
& -\int_{y_{g i}^{+}}^{R^{+}} U_{g}^{+}\left(R_{g}^{+}-y_{g}^{+}\right) d y_{g}^{+} \\
& =\frac{R_{g}^{t^{2}}}{K}\left\{\frac{3}{4}+\frac{1}{2} \ln \left|\frac{y_{i}}{R}\right|+\frac{1}{4}\left(\frac{y_{i}}{R}\right)^{2}-\frac{y_{i}}{R}\right\} \\
& -\frac{R_{g}^{+^{2}} U_{g i}^{+}}{2}\left\{\frac{y_{i}}{R} \cdot 1\right\}^{2}-0.204 \dot{R}_{g}^{+^{2}}
\end{aligned}
$$$$
\text { we obtain }
$$

from Equation $(6-6)$ to order $\left(y_{i} / R\right)^{2}$ since $\left(y_{i} / R\right)<<1$. Equation (6-5) with Equation (6-8) can be solved for $\mathrm{U}_{\tau \mathrm{g}}$ and $y_{i}$ by iteration.

As shown in Figure 12, one can now calculate the average void fraction over the entire cross section, summing the film and core contributions. Finally, one can calculate the pressure drop by the force balance relation:

$$
\frac{\mathrm{dP}}{\mathrm{dz}}=-\left[\frac{2 \mathrm{U}_{\tau \mathrm{g}}^{2} \rho_{\mathrm{g}}}{\mathrm{R}}+(1-\bar{a}) \rho_{\ell \mathrm{g}}\right] \text {. }
$$

Tables 1,2 , and 3 contain calculated and available experimental results for $\mathrm{dP} / \mathrm{dz}, \bar{a}$, and $\delta$ for the same input mean data. The effects of different input entrainment values and different values of $K$, the constant in the gas core velocity profile, are examined.

Schraub, Simpson, and Janssen ${ }^{31}$ reported the experimental values given in Table 1 for $E, d P / d z, \bar{a}$, and $\delta$. It is apparent, from Table 1 , that for $\bar{X}=0.38$ the best agreement between predicted and experimental results is obtained with $\mathrm{K}=0.3$ and the experimentally determined value for $\mathrm{E}$. These results show that the $\mathrm{dP} / \mathrm{dz}, \bar{a}$, and $\delta$ are strongly dependent upon the entrainment fraction. Results for other quality runs verify that $K=0.3$ produces the best overall agreement between calculated and experimental results for $X>30 \%$. For $X<30 \%$, it appears, from $F$ igures 13 and 14 , that $K=0.4$ produces better agreement. At first, one might attempt to specify $K$ as an empirical function of $\mathrm{X}$, varying from 0.4 (say) at low qualities to some lower value at higher qualities. This function would be merely an artifice, clearly not in line with the suggestion of Alia, et al., ${ }^{10}$ that more core droplets (lower mean quality) should produce a lower value for K. Based on the data of Schraub. Simpson, and Janssen, ${ }^{31}$ one could simply state that this computational scheme does not apply for $x<30 \%$. However, there is sufficient uncertainty in the measured value of entrainment to question this trend with quality, and to ask how the trend would be affected if the entrainment fraction at $\mathrm{X}<30 \%$ were less than measured. For the $X=22 \%$ run, for example, the calculated values of $\delta$ and $\left|\frac{d P}{d z}\right|$ would be correspondingly raised and the calculated value of $\bar{a}$ would be lowered, all three thereby coming into better agreement with the data.

Calculations from the data of Alia, et al., ${ }^{10}$ are shown in Table 2. Unfortunately, only experimental $\mathrm{dP} / \mathrm{dx}$ was reported by Alia, et al., for these flows. However, these results confirm that $K=0.3$ predicts $\mathrm{dP} / \mathrm{dx}$ in closer agreement with experimental values than $K=0.4$. Also, the $\Pi_{1}$ entrainment correlation produces a much higher entrainment than $\Pi_{3}$ which causes much lower pressure drops, in better agreement with the reported experimental values.

In Table 3, with the data of Gill, et al., ${ }^{6}$ it is found that the $\Pi_{1}$ entrainment correlation (with which the experimental entrainment data of Gill, et al., agrees) and $K=0.3$ produce a $\mathrm{dP} / \mathrm{dx}$ value in best agreement with experiment. Also, predicted $\delta$ is within $20 \%$ of the experimental value.

It is noted that Gill and Hewitt ${ }^{7}$ obtained asymptotic $\mathrm{dP} / \mathrm{dz}$ data on the same apparatus used by Gill, et al., ${ }^{6}$. Gill and Hewitt introduced the liquid at the tube center, while Gill, et al., introduced the liquid around the periphery. Consequently, $\mathrm{E}$ was higher and $\mathrm{dP} / \mathrm{dz}$ was lower for Gill and Hewitt than for Gill, et al. Again, $\mathrm{K}=0.3$ produces predicted $\mathrm{dP} / \mathrm{dz}$ in better agreement with experiment than $\mathrm{K}=\mathbf{0 . 4}$.

One must conclude from this discussion that $E$ and $\mathrm{dP} / \mathrm{dz}$ are intimately related and that with $\mathrm{K}=0.3$ and the known $\mathrm{E}, \mathrm{dP} / \mathrm{dz}$ can be closely predicted (within $25 \%$ of experimental value). (It is realized that the change from $K=0.4$ in Section 4 to $K=0.3$ in the present computations amounts to changing $K$ so as to absorb the inaccuracies of the phenomenological models in this computational method.)

On the other hand, one generally does not know $F$. except from a correlation. As discussed in Section 3, it is apparent that some entrainment data are rig and measurement technique dependent, making the $\mathrm{Il}_{1}$ and $\Pi_{3}$ correlations uncertain. Thus, the conclusion is reached that an $\mathrm{E}$ versus $\mathrm{dP} / \mathrm{dz}$ correlation is more universal. Of course, $\Pi_{1}$ and $\Pi_{3}$ entrainment correlations may be determined experimentally for a given rig in order that $\mathrm{dP} / \mathrm{dz}$ can be predicted more accurately from that rig. 

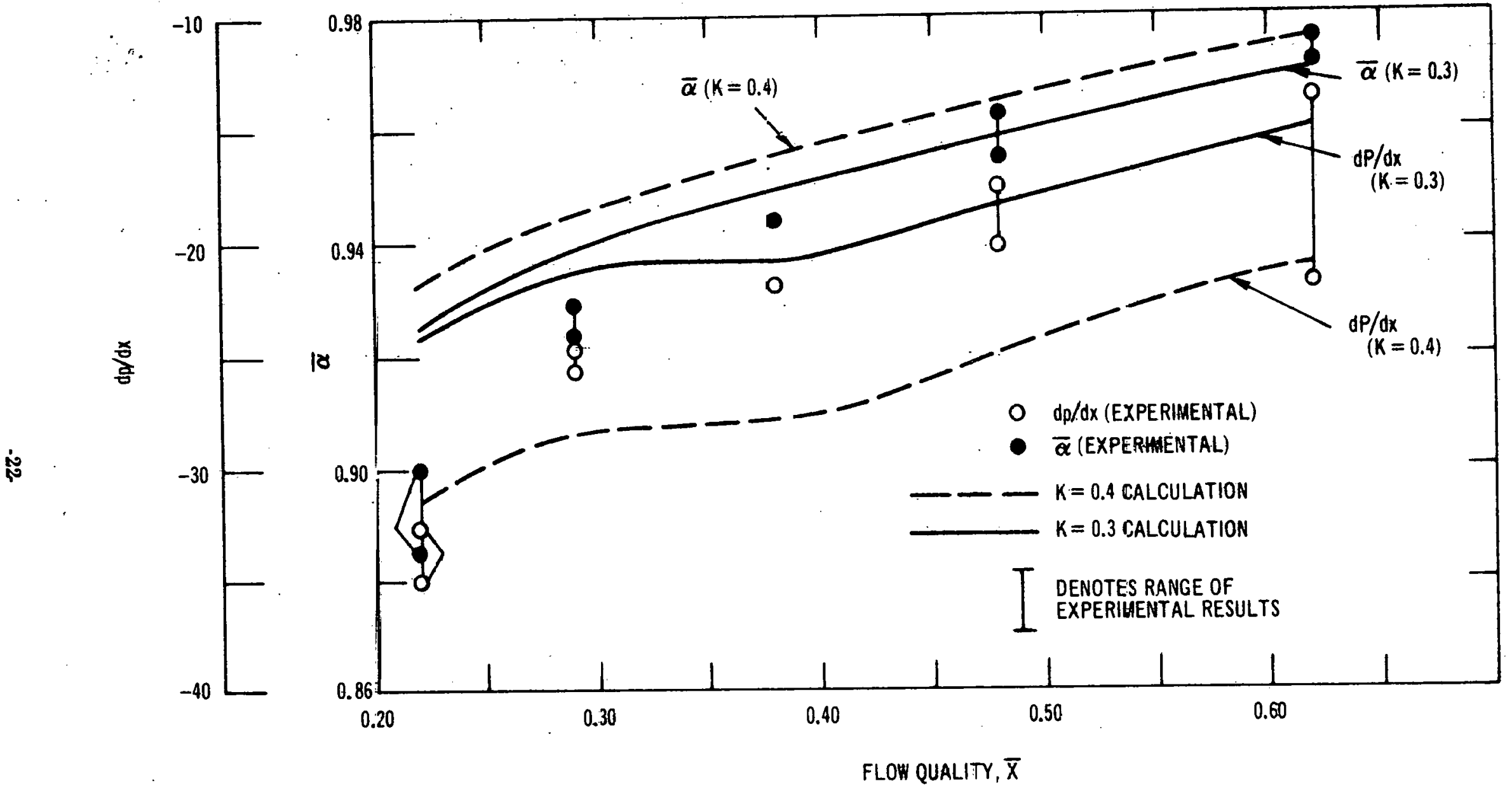

Figure 13. Comparison of Calculated and Experimental Pressure Drop and Void Fraction for the Data of Schraub, Simpson, and Janssen (Ref. 31) 


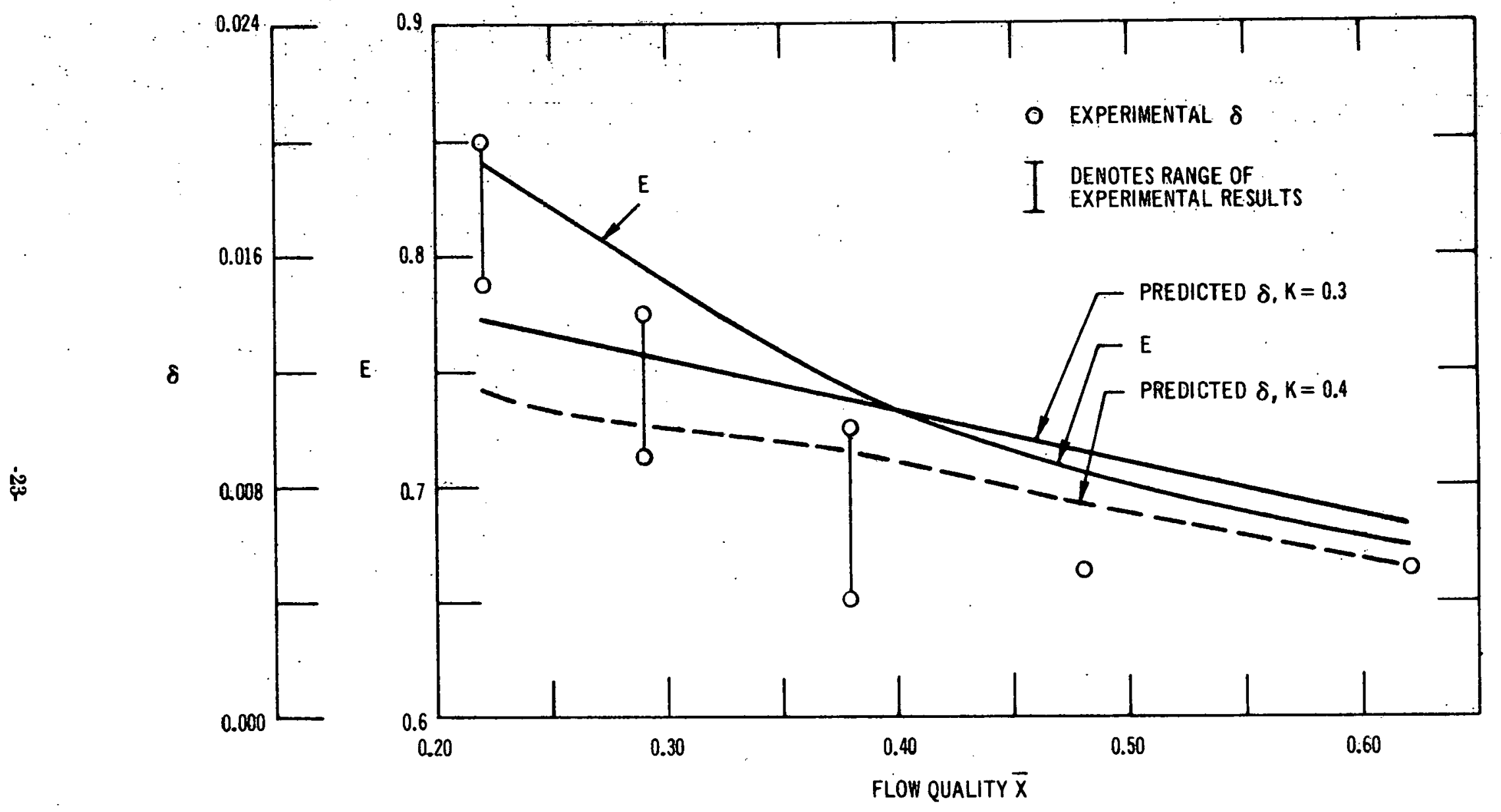

Figure 14. Comparison of Calculated and Experimental Liquid Film Thickness for the Data of Schraub, Simpson, and Janssen (Ref. 31) . 
Table 1

CALCULATED AND EXPERIMENTAL RESULTS

FOR THE ROUND TUBE DATA OF SCHRAUB, SIMPSON, AND JANSSEN

$$
\left(G_{g}=7.2 \times 10^{4} \mathrm{lb} / \mathrm{ft}^{2} \text {-sec }\right)
$$

Calculated

Experimental

\begin{tabular}{|c|c|c|c|c|c|c|c|c|c|c|c|}
\hline$\overline{\mathbf{x}}$ & $\begin{array}{l}\text { Entrainment } \\
\text { Correlation }\end{array}$ & $\mathbf{K}$ & E & $\begin{array}{c}\delta \\
\text { (in.) }\end{array}$ & $\begin{array}{c}\mathrm{U}_{\tau} \\
\text { (ft/sec) }\end{array}$ & $\bar{a}$ & $\begin{array}{c}\mathbf{d P} / \mathbf{d z} \\
\left(\mathbf{l b f} / \mathbf{f t}^{3}\right)\end{array}$ & $\begin{array}{c}\mathbf{d P} / \mathbf{d z} \\
\left(\mathbf{l b f} / \mathbf{f t}^{3}\right)\end{array}$ & $\bar{a}$ & $\begin{array}{c}\delta \\
\text { (in.) }\end{array}$ & \\
\hline 0.38 & $\Pi_{1}$ & 0.4 & 0.24 & 0.020 & 7.8 & 0.920 & -45 & .21 .9 & 0.945 & $\begin{array}{c}0.004 \\
\text { to } \\
0.010\end{array}$ & \\
\hline 0.38 & $\begin{array}{l}\text { Experi- } \\
\text { mental } \\
\text { Value }\end{array}$ & 0.4 & 0.74 & 0.009 & 6.2 & 0.956 & -28 & -21.9 & 0.945 & $\begin{array}{c}0.004 \\
\text { to } \\
0.010 \\
0.004\end{array}$ & . \\
\hline 0.38 & $\Pi_{1}$ & 0.3 & 0.24 & 0.023 & 6.7 & 0.907 & -35 & -21.9 & 0.945 & $\begin{array}{c}\text { to } \\
0.010\end{array}$ & \\
\hline 0.38 & $\begin{array}{l}\text { Experi- } \\
\text { mental }\end{array}$ & 0.3 & 0.74 & 0.011 & 5.2 & 0.949 & -21 & -21.9 & 0.945 & $\begin{array}{c}0.004 \\
\text { to }\end{array}$ &. \\
\hline & $\begin{array}{l}\text { Value } \\
\text { Experi- }\end{array}$ & & & & & & & -25.9 & & $\begin{array}{l}0.010 \\
0.009\end{array}$ & 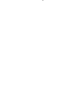 \\
\hline 0.29 & $\begin{array}{l}\text { mental } \\
\text { Value }\end{array}$ & 0.4 & 0.80 & 0.010 & 6.2 & 0.947 & -28 & $\begin{array}{l}\text { to } \\
-24.9\end{array}$ & 0.925 & $\begin{array}{c}\text { to } \\
0.014\end{array}$ & - \\
\hline 0.29 & $\begin{array}{l}\text { Experi- } \\
\text { mental } \\
\text { Value }\end{array}$ & 0.3 & 0.80 & 0.012 & 5.2 & 0.939 & -21 & $\begin{array}{c}-25.9 \\
\text { to } \\
-24.9\end{array}$ & 0.925 & $\begin{array}{c}0.009 \\
\text { to } \\
0.014\end{array}$ & \\
\hline 0.22 & $\begin{array}{l}\text { Expcri- } \\
\text { mental } \\
\text { Value } \\
\text { Experi- }\end{array}$ & 0.4 & 0.84 & 0.011 & 6.4 & 0.934 & -31 & $\begin{array}{c}-35.2 \\
\text { to } \\
-32.7 \\
-35.2\end{array}$ & $\begin{array}{c}0.900 \\
\text { to } \\
0.885 \\
0.900\end{array}$ & $\begin{array}{c}0.015 \\
\text { to } \\
0.020 \\
0.015\end{array}$ & \\
\hline 0.22 & $\begin{array}{c}\text { mental } \\
\text { Value } \\
\text { Experi- }\end{array}$ & 0.3 & 0.84 & 0.014 & 5.4 & 0.926 & -24 & $\begin{array}{c}\text { to } \\
-32.7 \\
-20.2\end{array}$ & $\begin{array}{c}\text { to } \\
0.885 \\
0.962\end{array}$ & $\begin{array}{c}\text { to } \\
0.020\end{array}$ & - \\
\hline 0.48 & $\begin{array}{l}\text { mental } \\
\text { Value } \\
\text { Expcri- }\end{array}$ & 0.4 & 0.71 & 0.008 & 5.9 & 0.965 & -25 & $\begin{array}{l}\text { to } \\
-17.8 \\
-20.2\end{array}$ & $\begin{array}{c}0.902 \\
\text { to } \\
0.954 \\
0.962\end{array}$ & 0.005 & . \\
\hline 0.48 & $\begin{array}{l}\text { mental } \\
\text { Value }\end{array}$ & 0.3 & 0.71 & 0.009 & 4.9 & 0.959 & -18 & $\begin{array}{c}\text { to } \\
-17.8\end{array}$ & $\begin{array}{c}\text { to } \\
0.954\end{array}$ & 0.005 & \\
\hline 0.62 & $\begin{array}{l}\text { Experi- } \\
\text { mental } \\
\text { Value }\end{array}$ & 0.4 & 0.67 & 0.005 & 5.5 & 0.975 & -21 & $\begin{array}{c}-21.8 \\
\text { to } \\
-13.9\end{array}$ & $\begin{array}{c}0.971 \\
\text { to } \\
0.975\end{array}$ & 0.005 & \\
\hline 0.62 & $\begin{array}{l}\text { Experi- } \\
\text { mental } \\
\text { Value }\end{array}$ & 0.3 & 0.67 & 0.007 & 4.5 & 0.970 & -15 & $\begin{array}{c}-21.8 \\
\text { to } \\
-13.9\end{array}$ & $\begin{array}{c}0.971 \\
\text { to } \\
0.975\end{array}$ & 0.005 & \\
\hline
\end{tabular}

Note: See Reference 31. 
Table 2

CALCULATED AND EXPERIMENTAL RESULTS

FOR THE ROUND TUBE DATA OF ALIA, et al.

\begin{tabular}{|c|c|c|c|c|c|c|c|c|c|}
\hline $\begin{array}{l}\text { Gas- } \\
\text { Liquid } \\
\text { Flow }\end{array}$ & $\overline{\mathbf{X}}$ & $\begin{array}{c}\text { Entrainment } \\
\text { Correlation }\end{array}$ & $\mathbf{K}$ & $\mathbf{E}$ & $\begin{array}{c}\delta \\
\text { (in.) }\end{array}$ & $\underset{(\mathrm{ft} / \mathrm{sec})}{\mathrm{U}_{\tau}}$ & $\bar{a}$ & $\begin{array}{c}\text { Calculated } \\
\mathbf{d P} / \mathbf{d z} \\
\left(\mathbf{l b f} / \mathbf{f t}^{3}\right)\end{array}$ & $\begin{array}{c}\text { Experimental } \\
\mathrm{dP} / \mathrm{dz} \\
\left(\mathbf{l b f} / \mathbf{f t}^{\mathbf{3}}\right)\end{array}$ \\
\hline $\begin{array}{l}\text { Argon- } \\
\text { water }\end{array}$ & 0.351 & $\Pi_{1}$ & 0.3 & 0.404 & 0.045 & 3.6 & 0.807 & -56 & 40.3 \\
\hline $\begin{array}{l}\text { Argon- } \\
\text { water }\end{array}$ & 0.351 & $\Pi_{3}$ & 0.3 & 0.228 & 0.053 & 3.9 & 0.788 & -65 & 40.3 \\
\hline $\begin{array}{l}\text { Argon- } \\
\text { water }\end{array}$ & 0.351 & $\Pi_{3}$ & 0.4 & 0.228 & 0.049 & 4.2 & 0.801 & .73 & 40.3 \\
\hline $\begin{array}{l}\text { Argon- } \\
\text { water }\end{array}$ & 0.786 & $\Pi_{1}$ & 0.3 & 0.312 & 0.013 & $2.4^{\circ}$ & 0.947 & -23 & -17.7 \\
\hline $\begin{array}{l}\text { Argon- } \\
\text { water }\end{array}$ & 0.786 & $\Pi_{3}$ & 0.3 & 0.213 & 0.013 & 2.5 & 0.944 & -25 & -17.7 \\
\hline $\begin{array}{l}\text { Argon-. } \\
\text { water }\end{array}$ & 0.786 & $\Pi_{3}$ & 0.4 & 0.213 & 0.012 & 2.9 & 0.951 & .32 & -17.7 \\
\hline $\begin{array}{l}\text { Argon- } \\
\text { alcohol }\end{array}$ & 0.294 & $\Pi_{1}$ & 0.3 & 0.999 & 0.001 & 1.8 & 0.896 & -16 & -31.8 \\
\hline $\begin{array}{l}\text { Argon- } \\
\text { alcohol }\end{array}$ & 0.294 & $\Pi_{3}$ & 0.3 & 0.383 & 0.062 & 4.0 & 0.741 & -67 & -31.8 \\
\hline $\begin{array}{l}\text { Argon- } \\
\text { alcohol }\end{array}$ & 0.294 & $\Pi_{3}$ & 0.4 & 0.383 & 0.057 & 4.3 & 0.754 & -75 & -31.8 \\
\hline $\begin{array}{l}\text { Argon- } \\
\text { alcohol }\end{array}$ & 0.786 & $\Pi_{1}$ & 0.3 & 0.882 & 0.051 & 2.0 & 0.969 & -15 & -13.7 \\
\hline $\begin{array}{l}\text { Argon- } \\
\text { alcohol }\end{array}$ & 0.786 & $\Pi_{3}$ & 0.3 & 0.330 & 0.016 & 2.5 & 0.942 & -24 & -13.7 \\
\hline $\begin{array}{l}\text { Argon- } \\
\text { alcohol }\end{array}$ & 0.786 & $\Pi_{3}$ & 0.4 & 0.330 & 0.012 & 2.9 & 0.950 & -31 & -13.7 \\
\hline
\end{tabular}

Note: See Reference 10. 
Table 3

CALCULATED AND EXPERIMENTAL RESULTS

FOR THE ROUND TABLE DATA OF GILL, et al., AND GILL AND HEWITT

(1-1/4-inch Inside Diameter, $\bar{X}=0.33$, $\dot{\bar{W}}=1500 \mathrm{lb} / \mathrm{h}$ )

Water Introduced on Wall (Ref. 6)

Experimental $E \approx 0.5$

Experimental

\begin{tabular}{|c|c|c|c|c|c|c|c|c|}
\hline $\begin{array}{l}\text { Entrainment } \\
\text { Correlation }\end{array}$ & $\mathbf{K}$ & $\mathbf{E}$ & $\begin{array}{c}\delta \\
\text { (ivi.) }\end{array}$ & $\begin{array}{c}U_{\tau} \\
(\mathrm{ft} / \mathrm{sec})\end{array}$ & $\bar{a}$ & $\begin{array}{c}\mathrm{dP} / \mathrm{dz} \\
\left(\mathrm{lbf} / \mathrm{ft}^{3}\right)\end{array}$ & $\begin{array}{c}\mathbf{d P} / \mathbf{d z} \\
\left(\mathbf{l b f} / \mathbf{f t}^{3}\right)\end{array}$ & $\begin{array}{c}\delta \\
\text { (in.) }\end{array}$ \\
\hline$\Pi_{1}$ & 0.4 & 0.488 & 0.012 & 20 & 0.958 & -58 & -33 & 0.013 \\
\hline$\Pi_{3}$ & 0.4 & 0.192 & 0.017 & 22 & 0.945 & .73 & -33 & 0.013 \\
\hline$\Pi_{1}$ & 0.3 & 0.488 & 0.015 & 16 & 0.950 & -11 & -33 & 0.013 \\
\hline$\Pi_{3}$ & 0.3 & 0.192 & 0.021 & 18 & 0.934 & -53 & -33 & 0.013 \\
\hline \multicolumn{9}{|c|}{ Water Introduced on Centerline (Ref. 7) } \\
\hline Experimental & 0.4 & 0.75 & 0.008 & 17 & 0.973 & -42 & -23 & 0.008 \\
\hline Value & 0.3 & 0.75 & 0.009 & 14 & 0.968 & -29 & -23 & 0.008 \\
\hline
\end{tabular}

Note: Scc Rcferences 6 and 7 . 


\section{CONCLUDING COMMFNTS}

During the course of this study, a low-pressure, horizontal, air-water channel was constructed at APED, as reported in Reference 40. Liquid film thickness and flon rate measurements indicated that when no void was observed in the liquid film, the zero void Von Karman theory as applied by Levy ${ }^{16}$ described the film thicknessflow rate relation. At the same time, no liquid entrainment or roll waves were observed. This is in agreement with the idea that entrainment and roll waves are related. It also suggests that when there is no entrainment, one must use the zero void film model, while the results of Section 2 require the consideration of void when there are roll waves and entrainment.

The apparently universal $G_{f}^{+}$versus $\delta^{+}$film flow ratethickness relationships described by the experimental data in Section 2 imply that there is a universal nondimensional velocity profile in the film. Hence, this is necessary proof that the Preston tube method of relating wall shear to impact pressure is valid for the film. Furthermore, this strengthens the confidence for using the Preston tube calibration presented by Schraub, Simpson, and Janssen ${ }^{31}$ as long as the probes are small enough to remain within the wall-film region.

The results from the computational scheme indicate that the entrainment fraction and pressure drop are closely related. When a known entrainment is input, the pressure drop is predicted within 25\% of the experimental value for $X>25 \%$. In many cases, the agreement is better than $25 \%$, and improves as the mean quality is increased. Since it is apparent that the entrainment fraction is rig-dependent to some degree, it is evident that the pressure drop will be affected accordingly; i.e., an increase in entrainment Irar. tion will produce a decrease in pressure drop. Thus, if one wishes to minimize pressure drop in a round tube, one can design the tlow inlet contiguration to promote liquid entrainment, such as introducing the liquid along the centerline, as done by Gill and Hewitt ${ }^{7}$. It was further found that when the pressure drop was closely predicted, the film thickness and average void fraction were also closely predicted.

Certainly this prediction scheme is more complicated than a simple pressure drop correlation such as the Lockhart-Martinelli ${ }^{41}$. However, more physical phenomena are considered so that the pressure drop prediction is sensitive to the entrainment fraction while also predicting the film - thickness. Also, the present study of the entrainment fraction indicates that the liquid surface tension is important in predicting the entrainment fraction from a given rig. This implies that the surface tension should influence the pressure drop-in contrast to the Lockhart-Martinelli correlation which includes no surface tension dependency. 


\section{NOMENCLATURE}

\begin{tabular}{|c|c|c|}
\hline D & $=$ & Tube diameter [L] \\
\hline $\mathrm{E}$ & $=$ & Entrainment fraction \\
\hline G & $=$ & Mass flux $\left[M / L^{2} T\right]$ \\
\hline $\mathrm{G}^{+}$ & $=$ & $\mathrm{G}_{\mathrm{f}} \delta / \mu_{\ell}$, dimensionless \\
\hline $\mathrm{g}$ & $=$ & Gravitational constant $\left[\mathrm{L} / \mathrm{T}^{2}\right]$ \\
\hline $\mathrm{L}$ & $=$ & Characteristic length; also axial length \\
\hline$\ell$ & $=$ & Mixing length [L] \\
\hline $\mathbf{P}$ & $=$ & P'icssuie $\left[\mathrm{F} / \mathrm{L}^{2}\right]$ \\
\hline $\mathrm{R}$ & $=$ & Tube radius [L] \\
\hline $\mathbf{r}$ & $=$ & Local radius $[\mathrm{L}]$ \\
\hline $\mathrm{U}$ & $=$ & Local velocity in flow direction $[\mathrm{L} / \mathrm{T}]$ \\
\hline $\mathrm{U}_{\mathrm{g}}^{+}$ & $=$ & $\mathrm{U} / \mathrm{U}_{\mathrm{Tg}}$, dimensionless \\
\hline $\mathrm{U}_{\ell}^{+}$ & $\equiv$ & $\mathrm{U} / \mathrm{U}_{\tau \ell}$, dimensionless \\
\hline $\mathrm{U}_{\tau \mathrm{g}}$ & $\equiv$ & $\sqrt{\tau \mathrm{w} / \rho_{\mathrm{g}},[\mathrm{L} / \mathrm{T}]}$ \\
\hline $\mathrm{U}_{\tau \ell}$ & $\equiv$ & $\sqrt{\tau \mathrm{w} / \rho_{\ell},[\mathrm{L} / \mathrm{T}]}$ \\
\hline$V_{\mathbf{r}}$ & $=$ & Turbulent radial drift velocity $[\mathrm{L} / \mathrm{T}]$ \\
\hline $\mathrm{X}$ & $=$ & Quality \\
\hline$y_{t}$ & $=$ & Distance measured from wall $[\mathrm{L}]$ \\
\hline$y_{g}^{+}$ & $\equiv$ & y II $\mathrm{Tg}_{\mathrm{g}} \mathrm{yy}_{\mathrm{g}}$, dimensionlcos \\
\hline$y_{l}^{+}$ & $\equiv$ & y $\mathrm{U}_{\tau \ell} / \nu_{\ell}$, dimensionless \\
\hline $\mathbf{z}$ & $=$ & Axial length [L] \\
\hline$a$ & $=$ & Local vuid fraction \\
\hline 匹 & $=$ & Averagre void fraction \\
\hline$\delta$ & $=$ & Time-averaged liquid film thickness $[\mathrm{L}]$ \\
\hline$\epsilon$ & $=$ & Diffusion coefficient \\
\hline$\mu$ & $=$ & Dynamic viscosity $\left[\mathrm{F} \cdot \mathrm{T} / \mathrm{L}^{2}\right]$ \\
\hline$\nu$ & $=$ & Kinematic viscosity $\left[\mathrm{L}^{2} / \mathrm{T}\right]$ \\
\hline$\rho$ & $=$ & Density $\left[\mathrm{M} / \mathrm{L}^{3}\right]$ \\
\hline$\sigma$ & $=$ & Surface tension $[\mathrm{F} / \mathrm{L}]$ \\
\hline$\tau$ & $=$ & Shear stress $\left[\mathrm{F} / \mathrm{L}^{2}\right]$ \\
\hline
\end{tabular}

\section{Subscripts}

$\begin{array}{ll}\mathbf{c} & =\text { Core } \\ \mathrm{q} & =\text { Tube centerline value } \\ \mathbf{f} & =\text { Film } \\ \mathrm{g} & =\text { Gas phase } \\ \mathrm{i} & =\text { Interface condition } \\ \ell & =\text { Liquid phase } \\ \max & =\text { Maximum value } \\ \mathbf{w} & =\text { Wall value. }\end{array}$




\section{ACKNOWLEDGMENTS}

This report concerns work sponsored by the U.S. Atomic Encrgy Commission (Contract AT(04-3)-189, Project Agreement 44) and conducted by Ceneral Electric Company, Atomic Power Equipment Division at San Jose,
California. Miss S. A. Kiernan and Mr. A. R. Lemerande contributed greatly in the handling of experimental data .nit in programming the prediction method.

\section{REFERENCES}

1. Taylor, N. H., Hewitt, G. F., and Lacey, P. M. C., "The Motion and Frequency of Large Disturbance Waves in Annular Two-Phase Flow of Air-Water Mixtures," Chem. Eng. Sci., 18, 537-552 (1963).

2. Hanratty, T. J., and Engen, J. M., "Interaction Between a Turbulent Air Stream and a Moving Water Surface," A.I.Ch.E.J., 3, 299-304 (1957).

3. Hanratty, T. J., and Hershman, A., "Initiation of Roll Waves," A.I.Ch.E.J., 7, 488-497 (1961).

4. Nedderman, R. M., and Shearer, C. J., "The Motion and Frequency of Large Disturbance Waves in Annular Two-Phase Flow of Air-Water Mixtures," Chem. Eng. Sci., 18, 661.670 (1963).

5. Singh, K., Crago, W. A., Moeck, E. O., and St. Pierre, C. C., "Liquid Flow Rates in Two-Phasc Flow of Steam and Water at 1000 psia," 17th Canadian Chemical Engineering Conference, October 16-18, 1967, Niagara Falls, Ontario.

6. Gill, L. E., Hewitt, G. F. and Hitchon, J. W., "Sampling Probe Studies of the Gas Core in Annular Two-Phase Flow - Part I," AERE-R-3954, 1962.

7. Gill, L. E., and Hewitt, G. F., "Sampling Probe Studies of the Gas Core in Annular Two-Phase Flow - Part III," AERE-M1202 (1967).

8. Bergles, A. E., and Roos, J. P., "Quarterly Progress Report, September 16, 1967 to March 15, 1968 Investigation of Boiling Flow Regimes and Critical Heat Flux," Dynatech Corp., Report NY0-3304-12.

9. Quandt, E. R., "Measurements of Some Basic Parameters in Two-Phase Annular Flow," A.I.Ch.E.J., 11, 311-318 (1965).

10. Alia, P., Cravarolo, L., Hassid, A., and Pedrocchi, E., "Phase and Velocity Distribution in Two-Phase Adiabatic Annular Dispersed Flow," CISE-R-109 (December 1966).

11. "Two-Phase Flow and Heat Transfer in Multirod Geometries, Tenth Quarterly Progress. Report, January 1 - March 31, 1968," GEAP-5497 (June 1968).

12. "Two-Phase Flow and Heal Transfer in Multirod Geometries, Fourth and Fifth Quarterly Progress Reports, July 26, 1965 - January 25, 1966," GE $\Lambda$ P 5056 (Fcbruary 1966).

13. "Two-Phase Flow and Heat Transfer in Multirod Geometries, Seventh Quarterly Progress Report, April 26 - July 25, 1966," GEAP-5207 (August 1966).
14. Cravarolo, L., Giorgini, A., Hassid, A., and Pedrocchi, E., "A Device for the Measurement of Shear Stress on the Wall of a Conduit - Its Application in the Mean Density Determination in Two-Phase Flow - Shear Stress Data in Two-Phase Adiabatic Vertical Flow." CISE-R-82 (February 1964).

15. Collier, J. G., and Hewitt, G. F., "Film Thickness Measurements," AERE-R-4684 (1964).

16. Levy, S., "Analysis of Various Types of Two-Phase Annular Flow, Part II - Prediction of Two-Phase Annular Flow with Liquid Entrainment," GEAP-4615 (May 1964).

17. Hewitt, G. F., "Analysis of Annular Two-Phase Flow: Application of the Dukler Analysis to Vertical Upward Flow in a Tube," AERE-R-3680 (1961).

18. Schraub, F. A., "Isokinetic Sampling Probe Technique Applied to Two-Component, Two-Phase Flow," GEAP-5287 (November 1966).

19. Rotta, J. C., "Turbulent Boundary Layers in Incompressible Flow," Progress in Aeronautical Sciences, Vol. 2 (1962).

20. Simpson, R. L., Ph.D. Thesis, Mechanical Engineering Department, Stanford University (1967).

21. Paleev, I. I., and Fillipovich, B. S., "Phenomena of Liquid Transfer in Two-Phase Dispersed Annular Flow," Int. J. Heat Mass Transfer 9, 1089-1093 (1966).

22. Brodkey, R. S., "The P̈henomena of Fluid Motions," p. 563, Addison-Wesley (1967).

23. Armand, A. A., "Resistance with Motion of a TwoPhase System Along Horizontal Tubes." Izv. Vses. Teplotekh Inst. No. 1, 16-23 (1964).

24. Huyghe, J., and Mondin, H., "Transfert de Chaleur par Melange de Liquide et de Gas en Convection Forcee Turbulente aves Faible Vaporization de la Phase Liquide," C. R. Hebd. Seanc. Acad. Sci, Paris 253, 395-397 (1.961.).

25. Collier, J. G., and Hewitt, G. F., "Data on the Vertical Flow of Air-Water Mixtures in the Annular and Dispersed Flow Regions, Part II: Film Thickness and Entrainment Data and Analysis of Pressure Drop Measurements," Trans Inst Chem Engr. 39, 127-136 (1961).

26. Magiros, P., and Dukler, A., "Entrainment and Pressurc Drop in Concurrent Gas-Liquid Flow," Proceedings of the 7th Midwestern Mechanics Conference, Vol. 1, pp 532-553 (1961). 
27. Minh, T. Q., and Huyghe, J. D., "Some Hydrodynamical Aspects of Annular Dispersed Flow: Entrainment and Film Thickness," Proceedings Symposium on Two-Phase Flow, Univ. Exeter, Excter, lingland, June 21-23, 1965, Vol. 2, C201-212.

28. Cousins, L. B., Denton, W. H., and Hewitt, G. F., "Liquid Mass Transfer in Annular Two-Phase Flow," AERE-R-4926 (1965).

29. Cousins, L. B., and Hewitt, G. F., "Liquid Phase Mass Transfer in Annular Two-Phase Flow Droplet Deposition and Liquid Entrainment," AERE-R-5657 (1968).

30. Singh, K., Crago, W. A., Moeck, E. O., and St. Pierre, C. C., "Liquid Film Flow Rates in I'wo-Phase Flow of Steam and Water at 1000 psia," 17th Canadian Chemical Engineering Conference, October 16-18, 1967, Niagara Falls, Ontario.

31. Schraub, F. A., Simpson, R. L., and Janssen, E., "Two-Phase Flow and Heat Transfer in Multirod Geometries-Air-Water Flow Structure Data for a Round Tube, Concentric and Eccentric Annulus, and Nine-Rod Bundle, Final Summary Report, GEAP-5739 (January 1969).

32. Steen, D. A., "An Investigation of the Transition from Annular to Annular-Mist Co-Current Two-Phase Downflow," M. S. Thesis, Dartmouth College (June 1964).

33. Alia, P., Cravarolo, L., Hassid, A., and Pedrocchi, E., "Some Spacer Effects in Annular and Cluster
Geometries in Two-Phase Annular-Dispersed Flow," CISE-R-110, Milan, Italy (December 1966).

34. Hinze, J. O., "Turbulence," McGraw-Hill, New York (1959).

35. Laufer, J., "The Structure of Turbulence in Fully Developed Pipe Flow," NACA TN 2954 (June 1953).

36. Wieghardt, K., "Uber die Wandschubspanning in turbulenten Reibungaschichten bei veranderlichen A ussendruck Kaiser Wilhelm Institüt fur Strömungsforschung," Gottingen, U. and M 6603 (December 1943); also E. A. Hirst and D. Coles, Proceedings of AFOSR-IFP-Stanford 1968 Turbulent Boundary Layer Prediction Conference, Vol. II (1968).

37. Gill, L. E., Hewitt, G. F., and Lacey, P.M.C., "Sampling Probe Studies of the Gas Core in Annular Two-Phase Hlow - Part II," AERE-R-3955 (1963).

38. Cousins, L. B., and Hewitt, G. F., "Liquid Phase Mass Transfer in Annular Two-Phase Flow: Radial Liquid Mixing," AERE-R-5693 (1968).

39. Sehmel, G. A., "Aerosol Deposition from Turbulent Airstreams in Vertical Conduits," Battelle Northwest Lab-578 (March 1968).

40. "Two-Phase Flow and Heat Transfer in Multirod Geometries, Twelfth Quarterly Progress Report July 1 . September 30, 1968," GEAP-5709 (November 1968).

41. Lockhart, R. W., and Martinelli, R. C., "Proposed Correlation of Data for Isothermal Two-Phase, Two-Component Flow in Pipes," Chem. Engr. Progr., Vol. 45, No. 1 (1947). 


\section{DISTRIBUTION}

Aerojet-General Corporation Nuclcar Products and Services Group P.O. Box 77

San Ramon, California 94583

Attn: H. Jaffe

Argonne National Laboratory Reactor Engincering Division 9700 South Cass $\Lambda$ venuc

Argonne, Illinois 60439

Attn: Dr. Paul Lottes

Argonne National Laboratory Reactor Engineering Division 9700 South Cass Avenue

Argonne, Mlinuis 60439

Attn: M. Petrick

Atomics International

P.O. Box 309

Canoga Park, California 91305

Attn: L. Bernath

Babcock \& Wilcox Company

Atomic Energy Division

P.O. Box 1260

Lynchburg, Virginia 24505

Attn: D.F. Judd

Brookhaven National Laboratory

Chemical Engineering Division

Upton, New York 11973

Attn: Dr. O.E. Dwyer

Columbia University

Department of Chemical Engineering

New York, New York 10027

Attn: J. Casterline

Combustion Engineering, Inc.

Nuclear Division

P.O. Box 500

Windsor, Connecticut 06095

Attn: Dr. P. Zmola

E.I. du Pont de Nemours and Company

Wilmington, Delaware 19898

Attn: J.S. Neill

Dynatech Corporation

17 Tudor Street

Cambridgo, Maosaohuoctto 02139

Attn: A. Bergles
1 General Electric Company

Research and Development Center

P.0. Box 8

Schenectady, New York 12301

Attn: Fred Staub

1 Knolls Atomic Power Laboratory

General Electric Company

P.0. Box 1072

Schenectady, New York 12301

Attn: Document Librarian

$1 \quad$ Geoscience Limited

410 South Cedros

Solano Beach, California

Attn: H. Poppendick

Massachusetts Institute of Technology

1 Department of Mechanical Engineering

Cambridge, Massachusetts 02139

Attn: Dr. W. Rohsenow

Massachusetts Institute of Technology

1 Department of Mechanical Engineering Cambridge, Massachusetts 02139

Attn: Dr. P. Griffith

New York University

Department of Mechanical Engineering

1 University Heights

New York, New York 10453

Attn: Dr. Novak Zuher

North Carolina State University

1 Department of Chemical Engineering

Raleigh, North Carolina 27607

Attn: Dr. J.K. Ferrell

Oak Ridge National Laboratory

1 P.O. Box X

Oak Ridge, Tennessee 37830

Attn: H.W. Hoffman

Pacific Northwest Laboratory

P.O. Box 999

$1 \quad$ Richland, Washington 99352

Attn: J. Batch

Rutgers, 'I'hc State University

1 College of Engintering

New Brunswick, New Jersey 08903

$\Lambda$ ttn: Dr. R.L. Peskin 
Stanford University

Dopartment of Mechanical Engineering

Stanford, California 94305

Attn: Dr. G. Leppert

TRW, Inc.

TRW Systems Group

Onc Spacc Park

Redondo Beach, California 90278

Attn: S.M. Zivi

University of Michigan

Department of Chemical and Metallurgical Engineering

Ann Ar̈bor, Michlgan 48103

Attn: R. Balzhiser

Westinghouse Electric Corporation

Atomic Power Division

Box 355

Pittsburgh, Pennsylvania 15230

Attn: L.S. Tong

Westinghouse Electric Corporation

Bettis Atomic Power Laboratory

P.O. Box 79

West Mifflin, Permsylvania 15122

Attn: S. Green

National Aeronautics \& Space Admin.

Lewis Research Center

21000 Brookpark Koad

Cleveland, Ohio 44135

Attn: R. Weltmann (SEPO)

National Aeronautics \& Space Admin.

Lewis Research Center

21000 Brookpark Road

Cleveland, Ohio 44135.

Attn:Librarian

\section{A. Amorosi, Director}

LMliblR Program Office

Argonne National Laboratory

9700 South Cass Avenue

Argonne, Illinois 604.39

Atomic Energy of Canada Limited

Chalk River, Ontario, Canada

Attn: G.A. Wikhammer

U.S. Atomic Energy Commission

Division of Reactor Development and Technology

Washington, D.C. 20545

Attri: R.M. Scroggins
$1 \quad$ U.S. Atomic linergy Commission

Division of Reactor Development and I'echnology Washington,D.C. 20545

Attn: N. Todreas

1 U.S. Atomic Energy Commission

Division of Reactor Development and Technology

Washington, D.C. 20545

Attn: Water Projects Branch

U.S. Atomic Energy Commission

1

1 Division of Reactor Development and Technology Washington, D.C. 20545

Alut: Research \& Development Branch

U.S. Atomic Energy Commission

2 Division of Safety Standards

Washington, D.C. 20545

Attn: R. Impara

Atomic Energy Commission

1 P.O. Box 62

Oak Ridge, Tennessee

Centre d'Etudes Nucleaires

2

Chemin des Martyrs

2 Grenuble (Istere)

France

Attn: M. Mondin

CISE

Casella Postale 3986

3 - Milano (Segrate)

Italy

Attn: Prof. M. Silvestri

MAN

Abholfach

Nurnberg 2

1 Germany

Attn: Dr. Mayinger

SNECMA

1

Division Atomique

22, Quai Gallieni

1 Suresnes (Seine)

France

Attn: M. Foure

2 Technische Hogeschool Eindhoven

11

P.0. Box 313

Eindhoven

Netherlands

Attn: Prof. Dr. M. Bogaardt 
$\Lambda \mathrm{E}$ :-Kernenergieversuchsanlage 8752 Grosswelzheim (Unterfranken)

Germany

Attn: Dr. Kirchenmayer

CNEN

Rome

Via Belisario, 15

Italy

Attn: M. Bianchi

Alsthom

38 avenue Kleber

Paris $16 \mathrm{e}$

France

Attn: M.P. Domenjoud

Centre d'Fitudes Nucleaires de Saclay

B.P. no 2

Gif-sur-Yvette (S\&O)

France

Attn: MJ. Horowitz

FIAT

Sezione Energia Nucleare

Via Settembrini 235

Torino

Italy

Attn: M.G. Cesoni
1 Reactor Centrum Nederland

112 Scheveningseweg

's Gravenhage

Netherlands

Attn: Prof. Dr. M. Bogaardt

1

ANSALDO

l

Direzione Generale

Piazza Carignano 2

Genova

1 Italy

Attn: Dr. F. Cristofori

EURATOM

2

1 Direction fenerale, R\&F

51 , rue Belliard

Bruxelles

Belgium

Attn: Dr. P. Kruys

1

EURATOM

Casella Postale 1

Ispra (Varese)

Italy

Attu: M.R. Morin 